Check for updates

Cite this: J. Mater. Chem. B, 2020 8, 1589

Received 1st November 2019 Accepted 11th December 2019

DOI: $10.1039 / c 9 t b 02434 d$

rsc.li/materials-b

\section{Self-defending additively manufactured bone implants bearing silver and copper nanoparticles}

\author{
I. A. J. van Hengel, (D)*a M. W. A. M. Tierolf, ${ }^{a}$ V. P. M. Valerio, ${ }^{a}$ M. Minneboo, ${ }^{a}$ \\ A. C. Fluit, ${ }^{b}$ L. E. Fratila-Apachitei, ${ }^{a}$ I. Apachitei ${ }^{a}$ and A. A. Zadpoor (D) ${ }^{a}$
}

\begin{abstract}
Effective preventive measures against implant-associated infection (IAI) are desperately needed. Therefore, the development of self-defending implants with intrinsic antibacterial properties has gained significant momentum. Biomaterials biofunctionalized with silver (Ag) have resulted in effective antibacterial biomaterials, yet regularly induce cytotoxicity. In this study, the use of both Ag and copper (Cu) nanoparticles (NPs) on $\mathrm{TiO}_{2}$ surfaces was investigated to generate antibacterial and osteoconductive biomaterials. Hence, additively manufactured Ti-6Al-4V volume-porous implants were biofunctionalized with plasma electrolytic oxidation (PEO) through the incorporation of varying ratios of $\mathrm{Ag}$ and/or Cu NPs in the $\mathrm{TiO}_{2}$ layer covering the implant surface. For all experimental groups, the surface morphology, chemical composition, ion release profile, generation of reactive ion species, antibacterial activity against methicillinresistant Staphylococcus aureus (MRSA) in vitro and ex vivo, as well as the response of pre-osteoblastic MC3T3-E1 cells in metabolic activity and differentiation assays were determined. PEO biofunctionalization resulted in rough and highly porous surfaces that released $\mathrm{Ag}$ and $\mathrm{Cu}$ ions for 28 days and generated hydroxyl as well as methyl radicals. A strong synergistic bactericidal behavior between $\mathrm{Ag}$ and $\mathrm{Cu}$ ions was detected, which allowed to decrease the concentration of $\mathrm{Ag}$ ions by 10 -fold, while maintaining the same level of antibacterial activity. Antibacterial agar diffusion and quantitative assays indicated strong antibacterial activity in vitro for the implants containing $\mathrm{Ag}$ and $\mathrm{Ag} / \mathrm{Cu}$, while no antibacterial activity was observed for implants bearing only Cu NPs. Moreover, the biofunctionalized implants with ratios of up to $75 \% \mathrm{Ag}$ and $25 \% \mathrm{Cu}$ NP totally eradicated all bacteria in an ex vivo model using murine femora. Meanwhile, the biofunctionalized implants did not show any signs of cytotoxicity, while implants bearing only Cu NPs improved the metabolic activity after 7 and 11 days. The biomaterials developed here, therefore, exploit the synergistic behavior of $\mathrm{Ag}$ and $\mathrm{Cu}$ to simultaneously offer strong antibacterial behavior while fully mitigating the cytotoxicity of $\mathrm{Ag}$ against mammalian cells.
\end{abstract}

\section{Introduction}

Implant-associated infection (IAI) is one of the most devastating complications for patients with orthopedic implants. Despite extensive preventive methods and antibiotic prophylaxis, up to $2.5 \%$ of primary hip and knee replacements and $10 \%$ of revision surgeries are complicated by IAI. ${ }^{1}$ The prevalence of IAI is anticipated to increase, given an aging and progressively obese population that requires joint replacement surgeries at younger age as well as a rapid development of bacterial resistance against antibiotics, leading to persistent and difficult-to-treat infections. ${ }^{2}$ Moreover, IAI accounts for extremely high healthcare costs, which

\footnotetext{
${ }^{a}$ Additive Manufacturing Laboratory, Department of Biomechanical Engineering, Faculty of Mechanical, Maritime and Materials Engineering, Delft University of Technology, Delft, The Netherlands. E-mail: i.a.j.vanhengel@tudelft.nl

${ }^{b}$ Department of Medical Microbiology, University Medical Center Utrecht, Utrecht, The Netherlands
}

are projected to be $\$ 1.62$ billion in the US alone by $2020 .^{3}$ The development of orthopedic implants that minimize the risk of IAI are, therefore, of utmost importance.

To prevent the bacterial colonization of the implant surface, orthopedic implants with intrinsic antibacterial properties are being developed. ${ }^{4}$ Since in this case the antibacterial agents are applied directly at the implantation site, the required dose is lower as compared to systemic intake, thereby decreasing the side effects. ${ }^{5}$ Inorganic nanoparticles (NPs), such as silver (Ag) and copper $(\mathrm{Cu})$ have been explored as alternatives to antibiotics that suffer from ever increasing bacterial resistance. ${ }^{6,7}$ The large surface area of NPs leads to their amplified oxidation on the implant surface while the accompanying release of metallic ions induces strong bactericidal effects. ${ }^{8}$

To incorporate antibacterial agents, the surface of the metallic implant needs to be biofunctionalized. While the modification of the surface chemistry and morphology may be used to prevent bacterial adhesion, the incorporation of 
antibacterial agents on the implant surface allows for actively targeting the bacteria residing in the adjacent tissues. ${ }^{9,10}$ To produce an antibacterial surface, the antibacterial agent is either embedded on the implant surface, incorporated in a conversed surface layer, or applied as a coating. ${ }^{11}$ Through these approaches, functional, and antibacterial biomaterials have been synthesized containing antibiotics, inorganic NPs, or antimicrobial peptides. ${ }^{12-14}$

Among surface biofunctionalization techniques, plasma electrolytic oxidation (PEO) is a single-step, electrochemical process that is particularly suited for the biofunctionalization of highly porous metallic biomaterials, such as additively manufactured porous titanium implants. ${ }^{8}$ The use of additive manufacturing (AM) facilitates the fabrication of novel implant designs that allow for the fine-tuning of the mechanical properties such that stress shielding is prevented and bony ingrowth is enhanced. ${ }^{15-17}$ However, due to their vast surface area, these porous implants are prone to bacterial adhesion, and, therefore, require surface biofunctionalization.

During PEO, the native metallic oxide layer (i.e., $\mathrm{TiO}_{2}$ ) is vastly expanded, resulting in a bioactive surface with high levels of nano/micro-porosity, enhanced roughness, and crystallized (i.e., rutile or anatase) $\mathrm{TiO}_{2}$ phase compositions. ${ }^{18,19}$ Addition of inorganic NPs during PEO results in a firmly attached and homogeneous layer of immobilized NPs on the implants surface, thereby preventing the free circulation of the NPS and associated adverse effects. Furthermore, the incorporation of NPs in the growing $\mathrm{TiO}_{2}$ layer during PEO enables the sustained release of metallic ions, contributing to prolonged antibacterial effects. ${ }^{20,21}$

Previous studies have demonstrated that PEO treatment using Ag NPs, indeed, results in highly effective antibacterial biomaterials. ${ }^{22-24} \mathrm{Ag}$ NPs are potent against a wide range of bacterial strains including methicillin-resistant strains that are often involved in IAI. ${ }^{25,26}$ Moreover, bacterial resistance against $\mathrm{Ag}$ is uncommon and rarely develops during treatment. ${ }^{27}$ However, Ag NPs may induce cytotoxicity against host cells including mesenchymal stromal cells and neutrophils. ${ }^{28-31}$ Meanwhile, Cu NPs have demonstrated antibacterial properties while simultaneously stimulating osteogenesis and angiogenesis. ${ }^{32}$ Moreover, there are reports in the literature regarding the synergistic effects of $\mathrm{Ag}$ and other antibacterial agents. ${ }^{33-35} \mathrm{We}$, therefore, hypothesized that there is a synergistic effect between $\mathrm{Ag}$ and $\mathrm{Cu}$ and that by exploiting those effects the antibacterial properties of implants can be enhanced, ultimately resulting in a reduced amount of the required Ag NPs and, thus, the mitigation of the cytotoxic effects.

\section{Experimental}

\subsection{Implant design and additive manufacturing}

Volume-porous Ti-6Al-4V implants were designed and fabricated according to a protocol and design rationale that we have presented elsewhere. ${ }^{8}$ Briefly, the implants of $4 \mathrm{~cm}$ in length and a diameter of $0.5 \mathrm{~mm}$ were manufactured by a selective laser melting (SLM) printer (SLM-125, Realizer, Borchem, Germany) using a YLM-400-AC Ytterbium fiber laser (IPG Photonics Corporation, Oxford, United States) in an argon atmosphere with less than $0.2 \%$ oxygen content. Medical-grade (grade 23, ELI) Ti6Al4V powder particles (AP\&C, Boisbriand, Quebec, Canada) with spherical morphology, particle sizes ranging from 10 to $45 \mu \mathrm{m}$, and a layer thickness of $50 \mu \mathrm{m}$ were used. SLM laser processing was performed with a laser power of $96 \mathrm{~W}$, a wavelength of $1070 \pm 10 \mathrm{~nm}$, and an exposure time of $300 \mu \mathrm{s}$, resulting in a laser spot size of $145 \mu \mathrm{m}$. Subsequently, loose powder particles were removed by vacuum cleaning and the implants were ultrasonicated at $35 \mathrm{kHz}$ in acetone, 96\% ethanol, and demineralized water for $5 \mathrm{~min}$ each.

\subsection{Surface biofunctionalization}

The surface of Ti6Al4V implants was modified by PEO, resulting in a uniform and highly porous superficial titanium oxide layer. The PEO electrolyte contained $0.15 \mathrm{M}$ calcium acetate $(\geq 99 \%$, Sigma-Aldrich, St. Louis, Missouri, United States) and $0.02 \mathrm{M}$ calcium glycerophosphate ( $\geq 99 \%$, Dr Paul Lohmann GmbH, Emmerthal, Germany) dissolved in demineralized water in which Ag NPs (65-75\% Ag, Sigma-Aldrich, St. Louis, Missouri, United States) and/or Cu NPs (99.8\% Cu, SkySpring Nanomaterials, Houston, Texas, United States) were dispersed at varying ratios with $3.0 \mathrm{~g} \mathrm{~L}^{-1}$ designated as $100 \%$, generating different experimental groups. SLM implants that did not receive any PEO biofunctionalization were designated as non-treated (NT). PEO biofunctionalization was performed without any NPs (PT), $3.0 \mathrm{~g} \mathrm{~L}^{-1}$ or $1.5 \mathrm{~g} \mathrm{~L}^{-1}$ $\mathrm{Ag}$ NPs (PT - Ag, PT - Ag 50), $3.0 \mathrm{~g} \mathrm{~L}^{-1} \mathrm{Cu}$ NPs (PT - Cu), and varying ratios of both $\mathrm{Ag}$ and $\mathrm{Cu} \mathrm{NPs}(\mathrm{PT}-\mathrm{Ag} \mathrm{Cu}, \mathrm{PT}-\mathrm{Ag} \mathrm{Cu} 7525$ and PT - Ag Cu 50 50).

The particle sizes of the NPs ranged between 7 and $25 \mathrm{~nm}$ for $\mathrm{Ag}$ NPs and 40 and $60 \mathrm{~nm}$ for $\mathrm{Cu}$ NPs while both particles displayed a spherical morphology. The PEO electrolyte was sonicated 2 times for $3 \mathrm{~min}$ and stirred in between for $5 \mathrm{~min}$ at $500 \mathrm{rpm}$ with a magnetic stirrer (IKA-Werke GmbH \& Co. KG, Staufen, Germany) and a stir bar of $40 \times 8 \mathrm{~mm}$ (VWR, Radnor, Pennsylvania, United States).

The implants were biofunctionalized by PEO using a custom-made laboratory setup that consisted of an AC power supply ( $50 \mathrm{~Hz}$, type ACS 1500, ET powder Systems Ltd, Chesterfield, UK), a data acquisition board (SCXI, National Instruments, Austin, Texas, United States) that connected the computer interface and power supply, and an electrolytic cell consisting of double-walled glass with two electrodes. PEO processing was performed under galvanostatic conditions at a current density of $20 \mathrm{~A} \mathrm{dm}^{-2}$ for $5 \mathrm{~min}$ in $800 \mathrm{ml}$ electrolyte. In this process, the implant functioned as the anode and a ring-shaped stainless steel formed the cathode. The electrolytic cell was cooled with a thermostatic bath and the temperatures ranged between 6 and $8{ }^{\circ} \mathrm{C}$ at the beginning and the end of the PEO process. To ensure homogeneous distribution of the particles, the electrolyte was stirred continuously at $500 \mathrm{rpm}$. During PEO processing, the voltage-time $(V-t)$ transients were recorded every second.

Following PEO biofunctionalization, the implants were rinsed in running tap water for $1 \mathrm{~min}$. Thereafter, the implants 
were sterilized by $30 \mathrm{~s}$ ultrasonication in ethanol, $5 \mathrm{~min}$ immersion and $30 \mathrm{~s}$ ultrasonication in demineralized water, and subsequently heat treated for $1 \mathrm{~h}$ at $110{ }^{\circ} \mathrm{C}$ in an oven (Nabertherm TR60, New Castle, United States).

\subsection{Characterization of the surface morphology and chemical composition}

The surface morphology of the biofunctionalized implants was analyzed using scanning electron microscopy (SEM, JSM-IT100LV, JEOL, Tokyo, Japan). The electron beam energy ranged between 5-20 kV and working distance of $10 \mathrm{~mm}$ was used. Prior to imaging, the specimens were sputtered with a gold layer of $5 \pm 2 \mathrm{~nm}$ to enhance their electrical conductivity. To analyze the chemical composition, spot analysis was performed with energy dispersive X-ray spectroscopy (EDS).

\subsection{Ion release kinetics}

To study the release kinetics of $\mathrm{Ag}$ and $\mathrm{Cu}$ ions, biofunctionalized specimens ( $n=3$ per group) were submerged in $1 \mathrm{ml}$ phosphatebuffered saline (PBS) in dark Eppendorf tubes. The specimens were kept in a water bath at $37{ }^{\circ} \mathrm{C}$ under static conditions. The PBS was collected and replaced after $12 \mathrm{~h}$ and 1, 2, 4, 7, 14, and 28 days. The collected PBS was acidified with 5\% nitric acid to dissolve all the ion species entirely. Subsequently, the ion concentrations were detected using inductively coupled plasmaoptical emission spectrometry (ICP-OES) using a PerkinElmer Optima 3000DV (PerkinElmer, Zaventem, Belgium).

\subsection{Electron paramagnetic resonance}

To elucidate whether the implants generated reactive oxygen species (ROS) that contribute to contact-killing of adhesive bacteria, the ROS formation from the implant surfaces was measured using an electron paramagnetic resonance (EPR) spectrometer (Bruker EMX Plus, Billerica, Massachusetts, United States). The implants $(n=2$ per group, length $=0.5 \mathrm{~cm})$ were inserted inside a quartz capillary tube and were placed inside the EPR spectrometer. First, the baseline spectrum of the implants itself was measured followed by the detection of the formed radicals, which was performed through the submersion of the implants in $10 \mu \mathrm{l}$ PBS containing $20 \mathrm{mM}$ spin trap 5,5-dimethylpyrroline $\mathrm{N}$-oxide (DMPO, Sigma-Aldrich, St. Louis, United States). The EPR measurements were performed using a frequency of 9.78 GHz, a sweep width of $100 \mathrm{G}$, a time constant of $163.8 \mathrm{~ms}$, a conversion time of $160 \mathrm{~ms}$, a modulation amplitude of $1 \mathrm{G}$, a modulation frequency of $100 \mathrm{kHz}$, a receiver gain of $60 \mathrm{~dB}$, an attenuation of $10 \mathrm{~dB}$, and a power of $20 \mathrm{~mW}$. The radical generation was analyzed every $10 \mathrm{~min}$ for $2.5 \mathrm{~h}$.

\subsection{Antibacterial assays}

2.6.1. Preparation of the bacterial inoculum. The bactericidal properties of the biofunctionalized biomaterials were evaluated in vitro and ex vivo against methicillin-resistant Staphylococcus aureus (MRSA, strain USA300). ${ }^{36}$ Bacterial inocula were prepared by the addition of a single colony into $3 \mathrm{ml}$ Tryptic soy broth (TSB) or cation-adjusted Mueller Hinton broth (CAMH) and incubated for $2 \mathrm{~h}$ at $37{ }^{\circ} \mathrm{C}$ while shaking at $120 \mathrm{rpm}$.
Subsequently, the optical density at $600 \mathrm{~nm}\left(\mathrm{OD}_{600}\right)$ was measured and the desired bacterial inoculum was prepared. The inoculum was quantified by plating 10-fold serial dilutions of $10 \mu \mathrm{l}$ triplicates on blood agar plates (Becton Dickinson, Franklin Lakes, United States) followed by overnight incubation and colony forming unit (CFU) quantification.

2.6.2. Agar diffusion assay. The antibacterial leaching activity of the implants was tested in an agar diffusion assay. Agar plates were poured from Luria broth (LB) containing $200 \mathrm{~g}$ tryptone, $100 \mathrm{~g}$ yeast powder, $240 \mathrm{~g}$ Agar No. 1 (all from Oxoid, ThermoFisher Scientific, Massachusetts, United States), and $200 \mathrm{~g} \mathrm{NaCl}$ dissolved in $20 \mathrm{~L}$ ultrapure water. A bacterial inoculum of $10^{7} \mathrm{CFU}$ per $\mathrm{ml}$ was prepared in TSB. Subsequently, bacteria were distributed over the agar plates using a cotton swab. Thereafter, $1.5 \mathrm{~cm}$ implants were pressed onto the agar surface and incubated at $37^{\circ} \mathrm{C}$ in a humid environment for $24 \mathrm{~h}$. Following incubation, the area of the zone of inhibition was analyzed using an image processing program (Photoshop CS6, Adobe, California, United States) to determine the antibacterial leaching activity ( $n=3$ per group).

2.6.3. Minimal inhibitory concentration (MIC) and minimal bactericidal concentration (MBC). In order to determine the MIC and $\mathrm{MBC}$ of $\mathrm{Ag}^{+}$and/or $\mathrm{Cu}^{2+}$ ions, $\mathrm{Ag}$ nitrate and $\mathrm{Cu}$ nitrate (both from Sigma-Aldrich, St. Louis, United States) were dissolved in $\mathrm{CAMH}$ broth. A bacterial inoculum of $\mathrm{OD}_{600} 0.09$ was prepared from which $65 \mu \mathrm{l}$ was transferred to $10 \mathrm{ml}$ of CAMH. Subsequently, two-fold serial dilutions were prepared in 96-well plates starting at initial concentrations of $2 \mathrm{mM}$ for $\mathrm{Ag}^{+}$and $80 \mathrm{mM}$ for $\mathrm{Cu}^{2+}$ respectively. Next, $50 \mu \mathrm{l}$ of bacterial inoculum and $50 \mu \mathrm{l}$ of both $\mathrm{Ag}^{+}$and $\mathrm{Cu}^{2+}$ dilutions were added to a 96-well plate and were incubated overnight at $37{ }^{\circ} \mathrm{C}$ under static conditions. The following day, the MIC was determined as the lowest concentration of $\mathrm{Ag}^{+}$and/or $\mathrm{Cu}^{2+}$ where no turbidities were present. To determine the $\mathrm{MBC}, 10 \mu \mathrm{l}$ aliquots of each well were plated on blood agar plates, incubated overnight at $37{ }^{\circ} \mathrm{C}$, and the numbers of $\mathrm{CFU}$ were determined. The $\mathrm{MBC}$ was defined as the lowest concentration of $\mathrm{Ag}^{+}$or $\mathrm{Cu}^{2+}$ ions without any bacterial colonies.

2.6.4. Bactericidal CFU count. The bactericidal activity of the biofunctionalized implants against adherent and planktonic bacteria was assessed by inserting 4 implants of $1 \mathrm{~cm}$ in a $200 \mu \mathrm{l}$ MicroAmp ${ }^{\mathbb{R}}$ Fast Reaction Tube (Life Technologies, Carlsbad, California, United States) with a bacterial inoculum of $2 \times 10^{3} \mathrm{CFU}$ in $100 \mu \mathrm{l} \mathrm{TSB}+1 \%$ glucose. Subsequently, the specimens ( $n=3$ per group) were incubated overnight under static conditions at $37{ }^{\circ} \mathrm{C}$. To quantify the number of the adherent CFU, the implants were rinsed 3 times in PBS, ultrasonicated in $200 \mu \mathrm{l}$ PBS for $3 \mathrm{~min}$. Subsequently, 10-fold serial dilutions of $10 \mu \mathrm{l}$ aliquots were plated on blood agar plates. The numbers of the non-adherent CFU present in the incubation medium were quantified by plating $10 \mu \mathrm{l}$ of the incubation medium of 10 -fold dilutions on blood agar plates. Following overnight incubation at $37{ }^{\circ} \mathrm{C}$, the number of CFUs was quantified.

2.6.5. Biofilm formation and characterization. The biofilm formation on the implants ( $n=2$ per group) was determined through static incubation at $37{ }^{\circ} \mathrm{C}$ in $100 \mu \mathrm{TSB}+1 \%$ glucose 
with $2 \times 10^{3} \mathrm{CFU}$ per $\mathrm{ml}$ for $24 \mathrm{~h}$. Subsequently, the implants were rinsed in PBS and fixated in McDowels fixative (4\% paraformaldehyde and $1 \%$ glutaraldehyde in $10 \mathrm{mM}$ phosphate buffer at $\mathrm{pH}$ 7.4). Prior to SEM imaging, the fixated implants were cleaned in demineralized water for $5 \mathrm{~min}$, dehydrated in $50 \%$ ethanol for $15 \mathrm{~min}, 70 \%$ ethanol for $20 \mathrm{~min}$, 96\% ethanol for $20 \mathrm{~min}$, and hexamethyldisilazane for $15 \mathrm{~min}$. Next, the implants were left to dry in air for $2 \mathrm{~h}$, sputtered with a gold layer of $5 \pm 2 \mathrm{~nm}$, and inspected by SEM.

2.6.6. Ex vivo experiments. The ex vivo antibacterial properties of the biofunctionalized implants were studied using murine femurs provided by the Central Laboratory Animal Institute (Utrecht University). The surrounding tissue was removed from the femurs, which were subsequently sterilized in $70 \%$ ethanol for $10 \mathrm{~min}$ and submerged in demineralized water for $10 \mathrm{~min}$. To insert the implants into the femur, a hole $(\varnothing 0.5 \mathrm{~mm})$ was drilled through the epicondyle into the intramedullary canal of the femur. Subsequently, the bone marrow was extracted using a syringe followed by $2 \mu$ injection of PBS into the medullary cavity. Then, the implants were inoculated with an inoculum of $200 \mathrm{CFU}$ in $2 \mu \mathrm{l}$ demineralized water, left to dry in air for $15 \mathrm{~min}$, and inserted into the femora.

To validate the system, $2 \mu$ l tetracycline $\left(50 \mathrm{mg} \mathrm{ml}^{-1}\right.$, SigmaAldrich, St. Louis, Missouri, United States) was inserted into the intramedullary cavity after implantation with an inoculated NT implant. To verify the proper sterilization of the femora, one femur was not implanted with an implant (negative control). Following implantation, the femora were incubated in $0.5 \mathrm{ml}$ Eppendorf tubes on a rotating platform at $37{ }^{\circ} \mathrm{C}$ for $24 \mathrm{~h}$ to simulate intraosseous fluid flow. Subsequently, the femora were homogenized in $800 \mu \mathrm{l}$ PBS using 15 zirconia beads ( $\varnothing 2 \mathrm{~mm}$, BioSpec, Bartlesville, Oklahoma, United States) with a MagNA Lyser (Roche Diagnostics, Risch-Rotkreuz, Switzerland) at $7000 \mathrm{rpm}$ for 2 cycles of $30 \mathrm{~s}$ and cooling on ice in between. Consequently, 10-fold serial dilutions of the homogenate were plated on blood agar plates, incubated overnight at $37^{\circ} \mathrm{C}$, and the CFU numbers were quantified.

\subsection{Cytotoxicity assays}

2.7.1. Cell seeding and culturing. Osteoblast-like cells (MC3T3-E1, Sigma-Aldrich) were pre-cultured for 7 days in $\alpha$-MEM supplemented with $1 \%$ penicillin-streptomycin and $10 \%$ fetal bovine serum (all from ThermoFisher, Waltham, Massachusetts, United States). The culture medium was refreshed every 2-3 days. The cells were seeded on $1 \mathrm{~cm}$ implants in $0.2 \mathrm{ml}$ tubes containing $1.5 \times 10^{5}$ MC3T3-E1 cells in $100 \mu$ l culture medium. The implants were then tilted every $20 \mathrm{~min}$ (for $2 \mathrm{~h}$ in total) at $37{ }^{\circ} \mathrm{C}$ in $5 \% \mathrm{CO}_{2}$ and were placed in a 48 well plate with $200 \mu \mathrm{l}$ of fresh medium. Following 2 days of culturing, osteogenic differentiation was induced by the addition of $50 \mu \mathrm{g} \mu \mathrm{l}^{-1}$ ascorbic acid and $4 \mathrm{mM} \beta$-glycerophosphate (both from Sigma-Aldrich). Thereafter, the medium was refreshed every 2-3 days.

2.7.2. Presto blue assay. The metabolic activity of the MC3T3-E1 cells was determined by a PrestoBlue assay (Thermofisher, Waltham, MA, United States) after 1, 3, 7, and 11 days. The implants were incubated in $200 \mu \mathrm{l}$ fresh culture medium with $20 \mu \mathrm{l}$ PrestoBlue cell viability reagent for $1 \mathrm{~h}$ at $37{ }^{\circ} \mathrm{C}$. Thereafter, the absorbance was measured at a wavelength of 530-595 nm with a Wallac plate reader (Victor X4, PerkinElmer, Massachusetts, United States).

2.7.3. Alkaline phosphatase (ALP) assay. The ALP activity of MC3T3-E1 cells on the implant was determined after 11 days. As such, the implants ( $n=4$ per group) were rinsed with PBS and inserted in $250 \mu \mathrm{l}$ PBS-Triton ( $8 \% \mathrm{NaCl}, 0.2 \% \mathrm{KCl}, 1.44 \%$ $\mathrm{Na}_{2} \mathrm{HPO}_{4}, 0.24 \% \quad \mathrm{KH}_{2} \mathrm{PO}_{4}$, and $0.1 \%$ Triton X-100). Subsequently, the implants were ultrasonicated for $10 \mathrm{~s}$ to dissociate the cells and were incubated with $100 \mu \mathrm{l} p$-nitrophenyl phosphate (pNPP, Sigma-Aldrich) for $10 \mathrm{~min}$ at $37{ }^{\circ} \mathrm{C}$. Thereafter, the reaction was stopped by the addition of $250 \mu \mathrm{l} \mathrm{NaOH}$. The absorbance was then measured at a wavelength of $405 \mathrm{~nm}$ with a Wallac plate reader (PerkinElmer). A standard curve was prepared by the addition of $100 \mu \mathrm{l}$ PBS-Triton and $250 \mu \mathrm{l} \mathrm{NaOH}$ to each well to determine the ALP activity and the total protein content was determined using a bovine serum albumin (BSA) protein assay kit (Invitrogen, California, United States). Subsequently, the ALP levels were normalized to the total protein content.

2.7.4. Cell morphology. To assess cell morphology on the implant's surface, the implants were fixated after 11 days in McDowels fixative and kept at $4{ }^{\circ} \mathrm{C}$. Prior to SEM imaging, the implants were rinsed twice in demineralized water for $5 \mathrm{~min}$ and dehydrated in ethanol (for $15 \mathrm{~min}$ in $50 \%$, for $20 \mathrm{~min}$ in $70 \%$, and for $20 \mathrm{~min}$ in $96 \%$ ). Subsequently, the implants were left to dry in air for $2 \mathrm{~h}$, sputtered with a gold layer $(5 \pm 2 \mathrm{~nm})$ and analyzed by SEM ( $n=2$ per group).

\subsection{Statistical analysis}

All data are expressed as mean \pm standard deviation. The statistical analyses were performed using GraphPad Prism (GraphPad Software, La Jolla, California, United States) with one-way ANOVA and Bonferroni post hoc test. Differences between groups were considered statistically significant at $p<0.05$.

\section{Results \& discussion}

\subsection{Surface morphology and PEO biofunctionalization}

Following SLM, SEM analysis demonstrated that the highly porous implants had partially molten or unmolten powder particles attached to the implant surface, which further enhanced the surface area of the implants (Fig. 1A). PEO biofunctionalization (Fig. 1B) resulted in similar $V-t$ curves recorded for all experimental groups (Fig. 1C). Up to the point of dielectric breakdown, the voltage increased with a rate of $14 \pm 1 \mathrm{~V} \mathrm{~s}^{-1}$ after which the ascent of the curve decreased to $0.49 \mathrm{~V} \mathrm{~s}^{-1}$ and plasma discharging started at $115 \pm 5 \mathrm{~V}$, resulting in a final voltage of $249 \pm 6 \mathrm{~V}$. SEM analysis demonstrated homogenous coverage of the implants surfaces with a micro-/nano-porous oxide layer (Fig. 1D). The addition of $\mathrm{Ag}$ and/or $\mathrm{Cu}$ NPs did not alter the surface morphology as compared to the PT implants. 

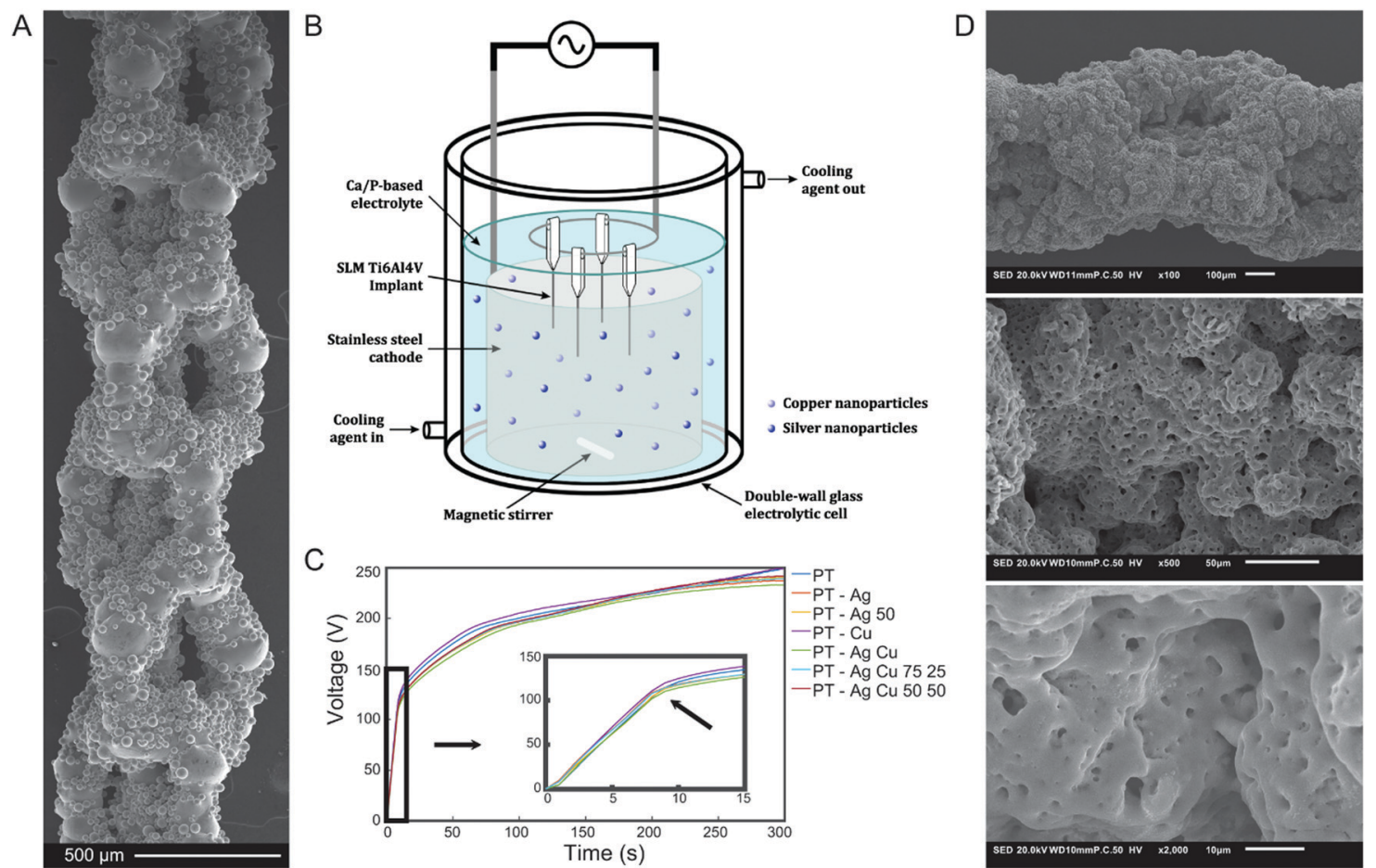

Fig. 1 (A) The surface morphology of a selective laser melted Ti-6Al-4V implant visualized using SEM imaging. (B) A schematic drawing of the electrolytic cell used for PEO biofunctionalization depicting the electrolyte species, silver and copper nanoparticles, and the arrangement of the implants and the cathode. (C) The recorded $V-t$ transients during the PEO biofunctionalization process of the selective laser melted implants with different electrolytes containing varying ratios of Ag and/or Cu NPs. (D) The SEM images of the surface morphology following $300 \mathrm{~s}$ of PEO biofunctionalization with $100 \times$ (top), $500 \times$ (middle) and $2000 \times$ (bottom) magnifications.

\subsection{Surface chemistry and phase composition of biofunctionalized implants}

The presence of $\mathrm{Ag}$ and $\mathrm{Cu}$ NPs on the implants after PEO biofunctionalization was demonstrated by EDS analysis (Fig. 2). Secondary electron and backscattering mode indicated a wide spread of $\mathrm{Ag}$ and/or $\mathrm{Cu}$ NPs on the surface which were fully embedded into the $\mathrm{TiO}_{2}$ surface layer. Point analysis demonstrated the presence of $\mathrm{Ti}, \mathrm{Al}, \mathrm{V}, \mathrm{Ca}$ and $\mathrm{P}$ in the surface layer for all biofunctionalized implants as well as $\mathrm{Ag}, \mathrm{Cu}$, and both $\mathrm{Ag}$ and $\mathrm{Cu}$ NPs for the PT $-\mathrm{Ag}$, PT $-\mathrm{Cu}$, and PT $-\mathrm{Ag} \mathrm{Cu}$ implants, respectively.

\subsection{Ion release and formation of reactive oxygen species}

In the first $24 \mathrm{~h}$, combined application of $\mathrm{Ag}$ and $\mathrm{Cu}$ NPs reduced the release of $\mathrm{Ag}^{+}$for the PT $-\mathrm{Ag} 50, \mathrm{PT}-\mathrm{Ag} \mathrm{Cu}, \mathrm{PT}-\mathrm{Ag} \mathrm{Cu} 75$ 25, and PT - Ag Cu 5050 groups as compared to the PT - Ag group $(p<0.05, p<0.01, p<0.001$ and $p<0.001$, respectively; Fig. 3A). Meanwhile, the release of $\mathrm{Cu}^{2+}$ was not affected by the presence of Ag NPs in the implant surface (Fig. 3B). The ion release continued for the entire duration of our measurements (i.e., 4 weeks). When the entire duration of the release experiment is considered, combining $\mathrm{Ag}$ and $\mathrm{Cu}$ NPs reduced the $\mathrm{Ag}^{+}$release from the PT - $\mathrm{Ag} \mathrm{Cu}, \mathrm{PT}-\mathrm{Ag} \mathrm{Cu} 75$ 25, and PT - $\mathrm{Ag} \mathrm{Cu} 5050$ groups as compared to the PT - Ag specimens $(p<0.05, p<0.01$ and $p<0.01$, respectively; Fig. $3 \mathrm{C}$ ) while the release of $\mathrm{Cu}^{2+}$ was enhanced for the PT - Cu group as compared to the PT - $\mathrm{Ag} \mathrm{Cu} 50$ 50 specimens ( $p<0.05$; Fig. 3D).
All biofunctionalized implants did generate both hydroxyl and methyl radicals, while the NT implants did not generate any oxygen radicals (Fig. 3E). Following the hydroxyl radical formation up to $2.5 \mathrm{~h}$, the groups containing Ag NPs demonstrated enhanced radical formation as compared to all other groups (Fig. 3F).

\subsection{Antibacterial assays}

After $24 \mathrm{~h}$ incubation, all the specimens containing Ag NPs demonstrated a zone of inhibition whereas the specimens from the groups NT, PT, and PT - Cu did not (Fig. 4A). The size of the inhibition zones did not differ significantly between all the groups containing Ag NPs (Fig. 4B). To explore the synergistic antibacterial behavior between $\mathrm{Ag}^{+}$and $\mathrm{Cu}^{2+}$ ions, we determined the MIC and MBC for $\mathrm{Ag}^{+}$and $\mathrm{Cu}^{2+}$ against MRSA USA300. The MIC for $\mathrm{Ag}^{+}$was $4 \mu \mathrm{M}$ and $5 \mathrm{mM}$ for $\mathrm{Cu}^{2+}$ while combining $2 \mu \mathrm{M} \mathrm{Ag}^{+}$and $2.5 \mathrm{mM} \mathrm{Cu}^{2+}$ prevented bacterial growth (Fig. 4C). Similarly, the MBC was $60 \mu \mathrm{M}$ and $10 \mathrm{mM}$ for $\mathrm{Ag}^{+}$and $\mathrm{Cu}^{2+}$ respectively while combining $30-0.47 \mu \mathrm{M} \mathrm{Ag}^{+}$with $0.63-5 \mathrm{mM} \mathrm{Cu}^{2+}$ resulted in total eradication of the bacterial inoculum (Fig. 4D).

The specimens from the PT - $\mathrm{Ag}, \mathrm{PT}-\mathrm{Ag} 50, \mathrm{PT}-\mathrm{Ag} \mathrm{Cu}$, and $\mathrm{PT}-\mathrm{Ag} \mathrm{Cu} 7525$ groups totally prevented bacterial adhesion, whereas those from the PT $-\mathrm{Ag} \mathrm{Cu} 5050$ group $\left(3.4 \times 10^{4} \mathrm{CFU}\right)$ showed a $3-\log$ reduction in the number of the adherent CFUs as compared to the specimens from the NT, PT, and PT - Cu groups $\left(1.7 \times 10^{8}, 2.5 \times 10^{8}\right.$ and $5.0 \times 10^{6} \mathrm{CFU}$ respectively; 


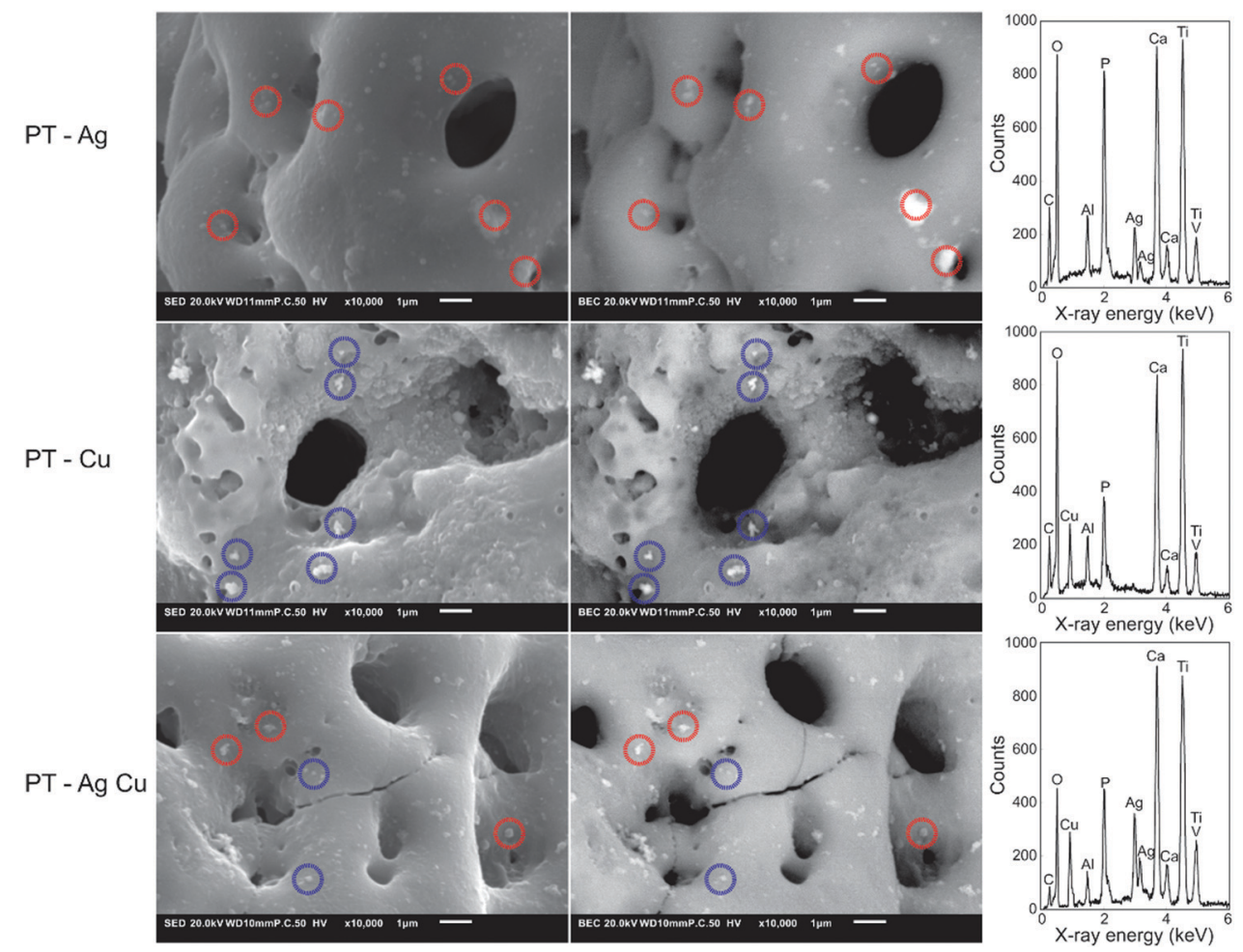

Fig. 2 The EDS analysis of the biofunctionalized implants containing Ag and/or Cu NPs. The locations of the Ag NPs (red circles) and Cu NPs (blue circles) on the implant surface were demonstrated by SEM using secondary (left) and backscattered (right) modes. Spot analysis confirmed the presence of $\mathrm{Ag}$ and $\mathrm{Cu}$ NPs as part of a surface layer containing Ti, Al, V, C, O, Ca, and P.

$p<0.001$; Fig. 4E). Similar results were obtained for the planktonic bacteria with PT - Ag Cu $5050\left(1.2 \times 10^{7} \mathrm{CFU}\right)$ demonstrating a 2-log reduction in the number of CFUs as compared to the NT, PT, and PT - Cu groups $\left(4.1 \times 10^{6}, 1.7 \times\right.$ $10^{8}$ and $1.6 \times 10^{7} \mathrm{CFU}$ respectively; $p<0.001$; Fig. $\left.4 \mathrm{~F}\right)$. The NT, $\mathrm{PT}$, and PT - Cu groups did not prevent biofilm formation on the implants where bacteria had stacked on top of each other in multiple layers (Fig. 5). The PT - Ag and PT - Ag Cu implants only showed sparsely attached bacteria, which were mostly entrapped inside the micropores.

To determine the ex vivo bactericidal activity, the implants were inserted into a murine femoral infection model (Fig. 6A). After $24 \mathrm{~h}$ of incubation, the specimens from the PT - Ag, $\mathrm{PT}-\mathrm{Ag} \mathrm{Cu}$, and PT - Ag Cu 7525 groups fully eradicated the bacterial inoculum while those from the PT - Ag 50 group $\left(3.7 \times 10^{5} \mathrm{CFU}\right)$ reduced the bacterial growth by two orders of magnitude as compared to the NT and PT specimens $\left(5.4 \times 10^{7}\right.$ and $6.1 \times 10^{6}$ CFU respectively; $p<0.001$; Fig. $\left.6 \mathrm{~B}\right)$.

\subsection{Cytocompatibility}

At day 1 and 3, the specimens from all groups demonstrated similar metabolic activity while after 7 days PT, PT - Ag 50, $\mathrm{PT}-\mathrm{Cu}$ and PT - Ag Cu 7525 exhibited enhanced metabolic activity as compared to the NT specimens $(p<0.001, p<0.05$, $p<0.001$ and $p<0.001$, respectively; Fig. 7A). Furthermore, the PT implants had enhanced metabolic activity as compared to the specimens from the PT $-\mathrm{Ag}, \mathrm{PT}-\mathrm{Ag} 50$, and PT $-\mathrm{Ag} \mathrm{Cu}$ 7525 groups ( $p<0.001, p<0.001$ and $p<0.01$, respectively).
The same held for the PT - Cu implants as compared to those from the $\mathrm{PT}-\mathrm{Ag}$ and $\mathrm{PT}-\mathrm{Ag} 50$ groups $(p<0.05$ and $p<0.01$, respectively;). After 11 days, the PT and PT - Cu implants displayed enhanced metabolic activity as compared to the NT implants $(p<0.001)$. The same held for the PT group as compared to PT - Ag, PT - Ag 50, and PT - Ag Cu 7525 groups ( $p<0.01, p<0.05$ and $p<0.01$, respectively) as well as for the PT - Cu group as compared to the PT - Ag, PT - Ag 50, and PT - Ag Cu 7525 groups ( $p<0.001$ ). Furthermore, the ALP activity after 11 days did not differ significantly between the different groups (Fig. 7B). The cell morphology after 11 days demonstrated that all surfaces had cell attachment on significant parts of their surfaces (Fig. 7C). Cells showed an elongated morphology and were found to span large surface areas.

\subsection{Discussion}

Given the widespread research into and the increasing demand for highly porous orthopedic implants manufactured by AM, there is an ever increasing need for implant surfaces with intrinsic antibacterial activity. While targeting adherent and surrounding bacteria, antibacterial agents should not induce adverse effects in the surrounding host tissue. Therefore, we explored the use of combining $\mathrm{Ag}$ and $\mathrm{Cu}$ NPs, incorporated onto the surface of AM Ti-6Al-4V implants through PEO biofunctionalization, to produce potent antibacterial surfaces. We report here that $\mathrm{Ag}$ and $\mathrm{Cu} \mathrm{NP}$ bearing implant surfaces with ratios of up to $75 \% \mathrm{Ag}$ and $25 \% \mathrm{Cu}$ NPs display leaching and direct-contact bactericidal activity against MRSA in vitro 
A

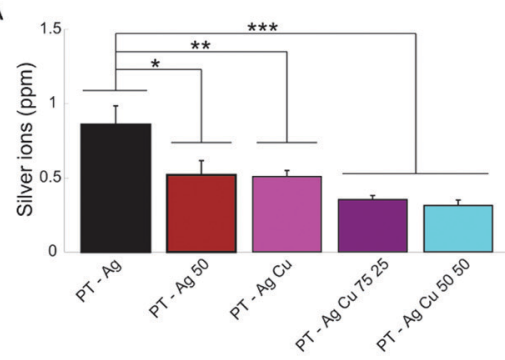

C

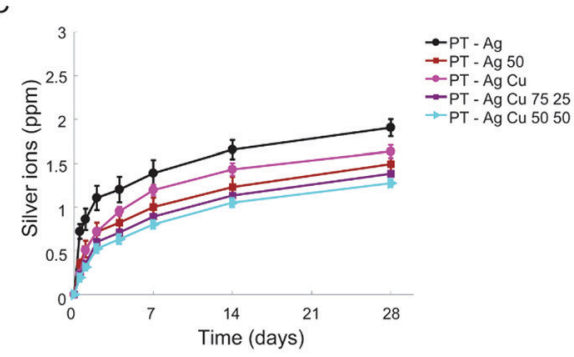

B

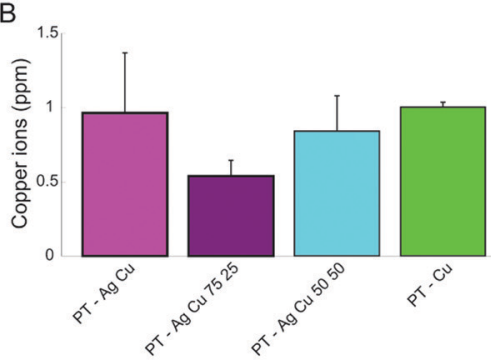

D

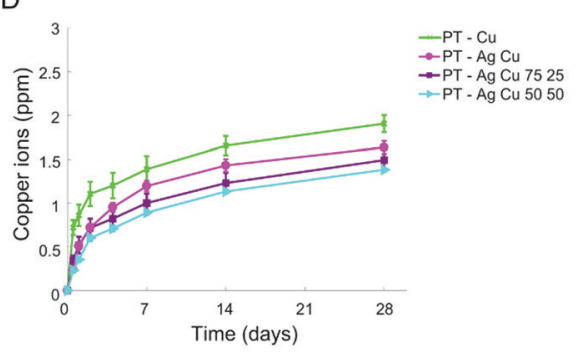

$\mathrm{F}$

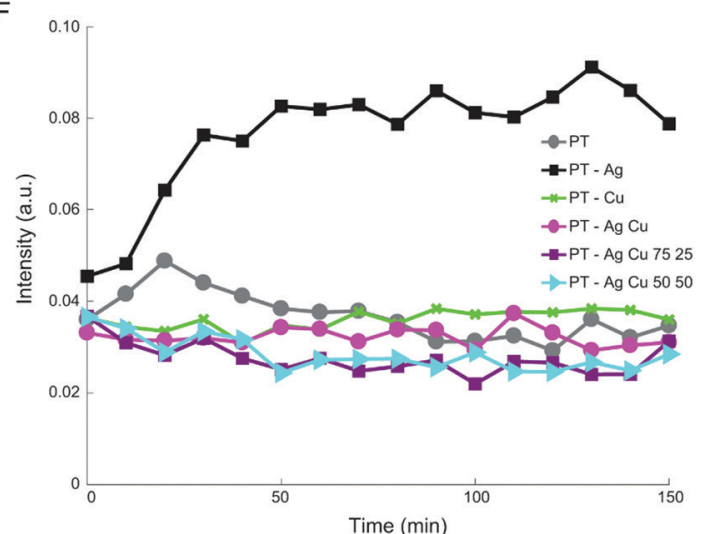

Fig. 3 The ion release profile and the generation of oxygen radicals. (A) The Ag and (B) Cu ions released from the biofunctionalized implants $(n=3)$ after $24 \mathrm{~h}$ in PBS were detected by ICP-OES. The cumulative release profiles of (C) Ag and (D) Cu ions for up to 28 days. (E) The generation of oxygen radicals by the implants measured using electron paramagnetic resonance and DMPO spin traps. Simulations of $\mathrm{OH}$ and $\mathrm{CH}_{3}$ radical spectra are depicted by DMPO-OH and DMPO- $\mathrm{CH}_{3}$ respectively. (F) $2 \mathrm{D}$ electron paramagnetic resonance spectrum demonstrating the oxygen radical formation for 150 min. ${ }^{*} p<0.05,{ }^{* *} p<0.01,{ }^{* *} p<0.001$.

and ex vivo, while not inducing cytotoxicity to pre-osteoblastic MC3T3-E1 cells.

To prevent IAI, immediate antibacterial activity is required as most infections arise at an early stage after implantation. ${ }^{37,38}$ In this study, the PT - Ag and PT - Ag Cu implants with ratios of up to 75\% $\mathrm{Ag}$ and $25 \% \mathrm{Cu}$ NPs fully eradicated adherent and planktonic bacteria in vitro and ex vivo within $24 \mathrm{~h}$. The prevention of bacterial adherence is essential to prevent biofilm formation, which gives rise to untreatable infections as the dose required to remove bacteria within a biofilm may be up to 1000 -fold higher as compared to planktonic bacteria. ${ }^{39}$ The fact that the biofunctionalized implants demonstrated strong antibacterial activity against MRSA is of clinical significance, since Staphylococci account for over $60 \%$ of IAI. ${ }^{29}$ Furthermore, IAI caused by MRSA are more difficult to treat resulting in a reduced number of cured patients after 1 year, as compared to methicillin-susceptible Staphylococcus aureus. ${ }^{40}$

To enhance the antibacterial activity of the implant, reduce cytotoxicity, and reduce the likelihood of bacterial resistance, we incorporated both $\mathrm{Ag}$ and $\mathrm{Cu}$ NPs onto the implant surfaces of our biofunctionalized implants. Combining $\mathrm{Ag}^{+}$and $\mathrm{Cu}^{2+}$ resulted in synergistic effects in the MIC and MBC assays by up to 2 and 10 -fold respectively. The same synergistic behavior resulted in the antibacterial results of the PT - Ag Cu 7525 group being comparable to those of the PT - Ag and PT - Ag Cu groups whereas the specimens from the PT - Ag Cu 5050 group resulted in 3-log and 2-log inhibition of the adherent and planktonic bacteria, respectively. Our results concur with previous studies where combining $\mathrm{Ag}$ and $\mathrm{Cu}$ enhanced the bactericidal activity against MRSA compared to either Ag or Cu. ${ }^{41,42}$ The underlying mechanism causing this synergistic effect remains to be elucidated. ${ }^{43}$

The sensitivity of bacteria to $\mathrm{Cu}$ is generally lower as compared to $\mathrm{Ag},{ }^{44}$ as reflected by the MIC-values obtained in this study. $\mathrm{Cu}$ is a cofactor in enzymatic reactions, ${ }^{45}$ required for proper bacterial cell metabolism, and therefore present in most bacterial culture media. ${ }^{46}$ At the same time, elevated 

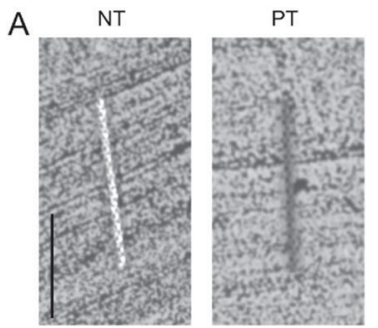

B

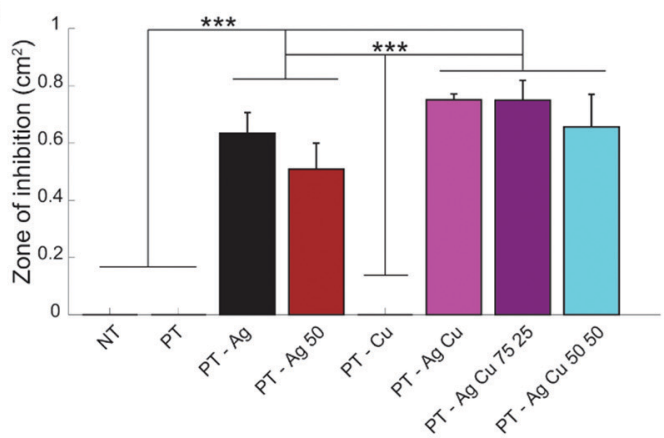

E
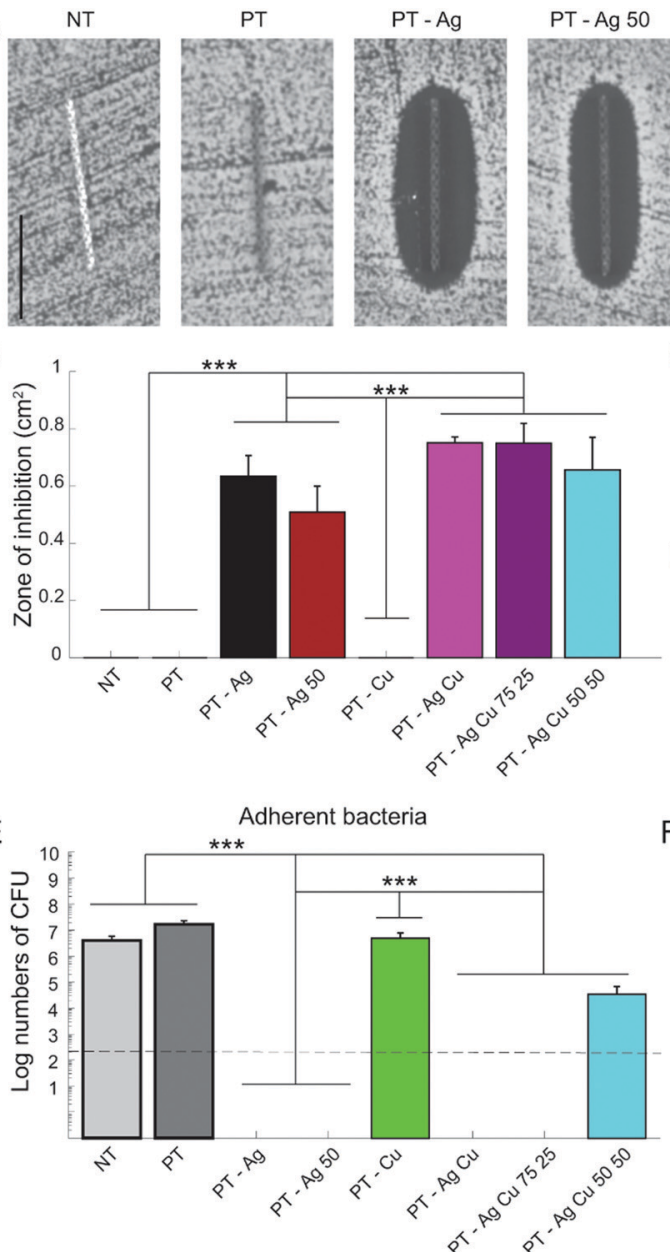
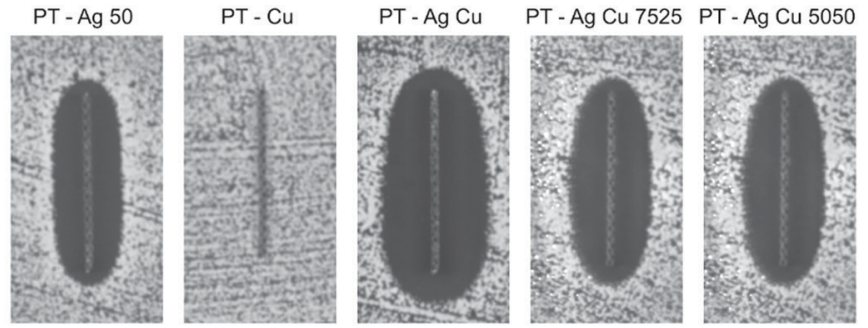

C

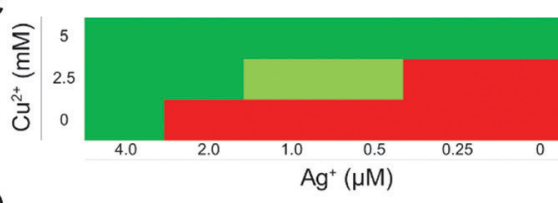

$\mathrm{D}$
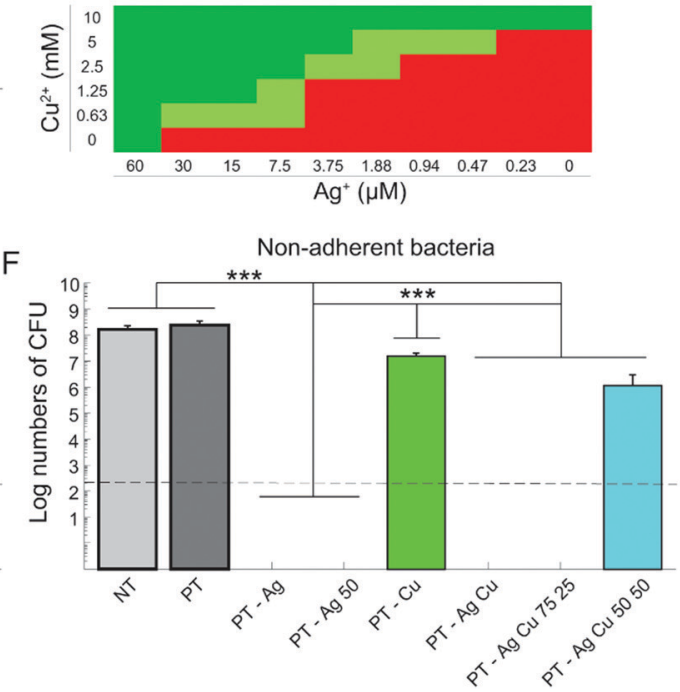

Fig. 4 The antibacterial leaching activity and quantification of bactericidal activity in vitro against MRSA USA300. (A) The images of the antibacterial inhibition zones around implants after 24 hours on agar plates using an inoculum of $10^{7} \mathrm{CFU}$ per ml. (B) Quantification of the area of the inhibition zones. (C) The minimum inhibitory and (D) bactericidal concentrations for the different concentrations of $\mathrm{Ag}^{+}$and/or $\mathrm{Cu}^{2+}$ ions. The bactericidal activity against (E) the Adherent and (F) planktonic bacteria. Dashed line represents the inoculum. ${ }^{*} p<0.05,{ }^{* *} p<0.01,{ }^{* *} p<0.001$. $n=3$ per group for all experiments. Scale bar $=1 \mathrm{~cm}$.

levels of freely circulating $\mathrm{Cu}$ are toxic to bacterial cells as they interfere with iron-sulfur cofactors, ${ }^{47}$ prevent other metals from binding to specific protein sites, ${ }^{48}$ and result in the generation of ROS. ${ }^{49}$ Therefore, bacteria have developed several $\mathrm{Cu}$ defense mechanisms ${ }^{50}$ including $\mathrm{Cu}$ exporting ATPases, multi-Cu oxidases, and resistance-nodulation-cell division efflux pumps that contributed to the development of highly Cu-resistant bacterial strains. ${ }^{51}$

Contrary to $\mathrm{Cu}, \mathrm{Ag}$ is not required for proper bacterial cell metabolism. Bacteria are, therefore, highly sensitive to $\mathrm{Ag}$ as is evident from 50 to 8000 times lower MIC-values as compared to $\mathrm{Cu}^{44} \mathrm{Ag}$ targets a wide spectrum of bacteria by disturbing protein function, disruption of the cell membrane, generation of ROS, and blocking iron-sulfur clusters resulting in disturbed bacterial homeostasis and DNA damage. ${ }^{28}$ Furthermore, Ag has demonstrated to make antibiotic-resistant Gram-negative bacteria, both in biofilms and planktonic cells, susceptible to antibiotic treatment again. ${ }^{52}$ Therefore, the synthesis of Ag-containing antibacterial biomaterials has been studied intensively and has been demonstrated to reduce the clinical infection rates in patients receiving large limb salvaging prostheses. ${ }^{53-55}$

However, mammalian cells are also susceptible to $\mathrm{Ag}$, meaning that cytotoxicity is a concern too. ${ }^{31}$ In this study, the PEO biofunctionalized implants containing Ag NPs did not show any signs of cytotoxicity against pre-osteoblastic cells and even demonstrated enhanced metabolic activity as compared to the NT implants after 7 days, while the PT and PT - Cu implants outperformed the Ag-containing implants after 7 and 11 days. Furthermore, no significant differences were observed on the ALP expression after 11 days of culture. All these results indicate that our surface bio-functionalized implants induce no cytotoxic effects against the pre-osteoblast cells. Indeed, the incorporation of $\mathrm{Ca}$ and $\mathrm{P}$ species onto the $\mathrm{TiO}_{2}$ implant surface layer during the PEO biofunctionalization process results in the formation of hydroxyapatite ${ }^{8}$ that together with the nano-/micro-porous structure of the created oxide layer enhance the osteogenic properties of the implants. ${ }^{56,57}$ Furthermore, the addition of $\mathrm{Cu}$ 

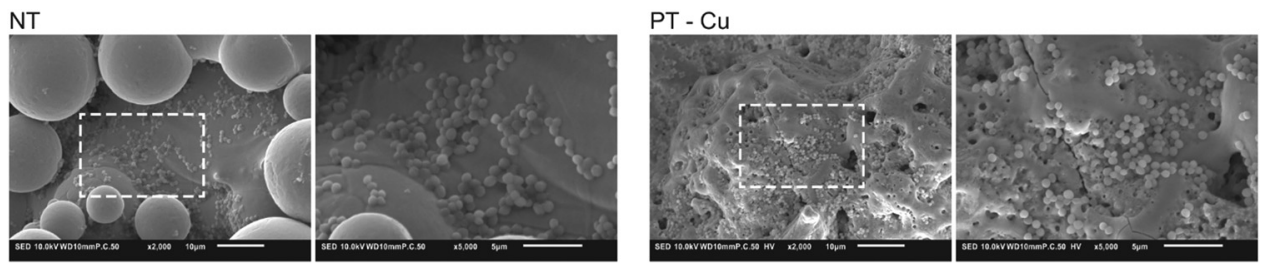

PT

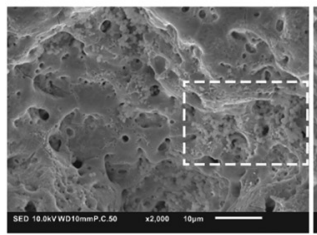

PT - Ag

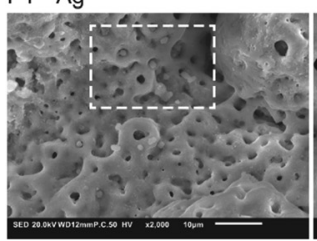

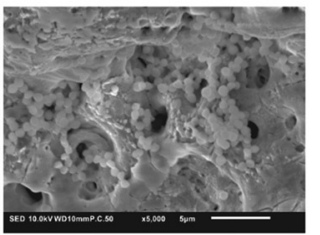

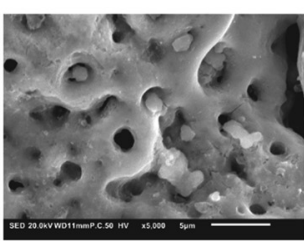

PT - Ag Cu
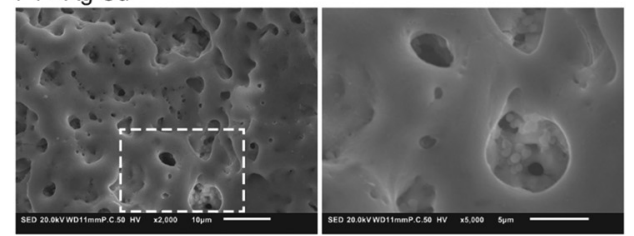

PT - Ag Cu 7525

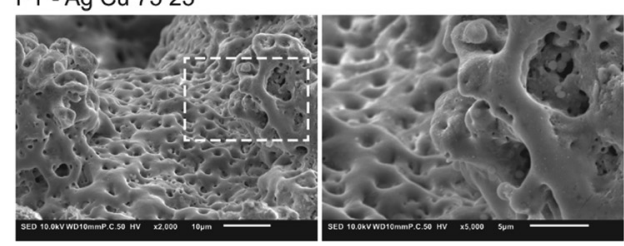

Fig. 5 Biofilm formation on the implants $(n=2)$ after incubation in TSB $1 \%$ glucose for $24 \mathrm{~h}$ visualized using low- $(2000 \times)$ and high-magnification $(8000 \times)$ SEM images.

A

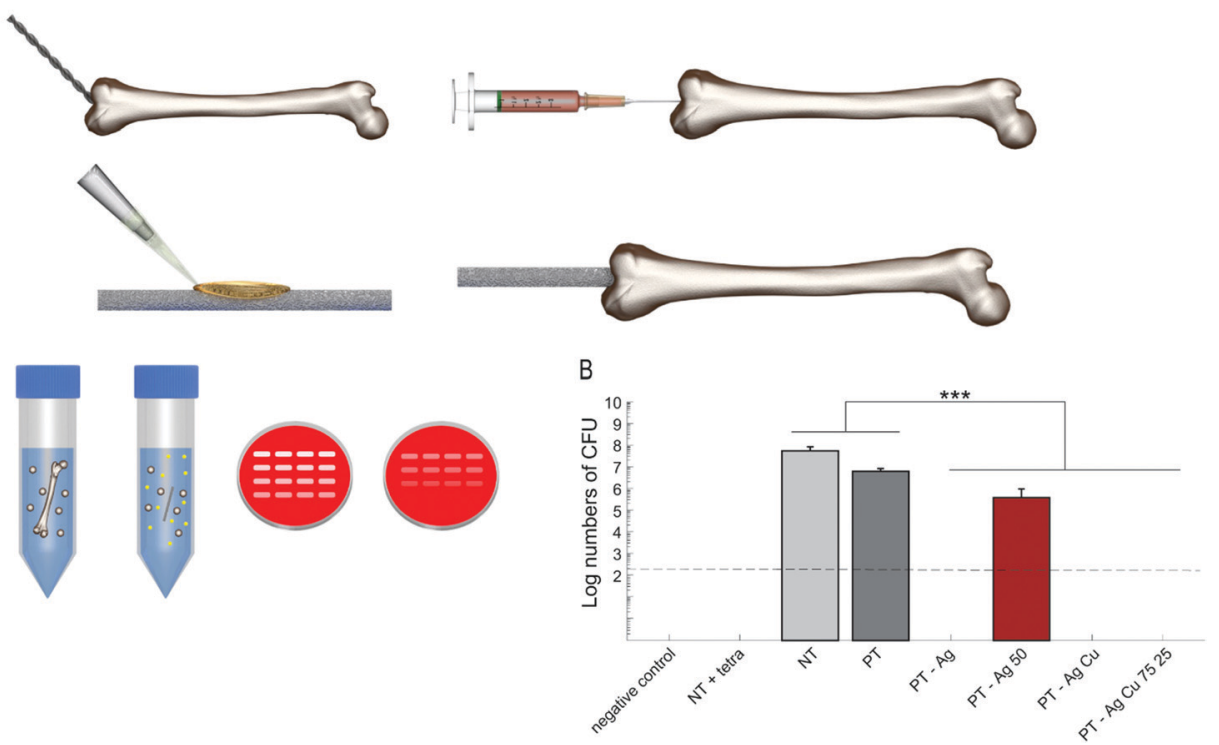

Fig. 6 The bactericidal capacity of implants in an ex vivo femoral mouse model against MRSA USA300. (A) A 0.5 mm hole was created to access the intramedullary cavity of mouse femora. Thereafter, the bone marrow was extracted and $2 \mu \mathrm{l} \mathrm{PBS}$ injected. The implants were inoculated with $2 \times 10^{2} \mathrm{CFU}$ and implanted intramedullary. After $24 \mathrm{~h}$ incubation, the femora were homogenized and 10 -fold serial dilutions of the homogenate were plated on blood agar plates. (B) The quantification of the number of CFU following $24 \mathrm{~h}$ incubation ex vivo. To confirm proper sterilization of the femurs, one femur without implant and bacterial inoculum was prepared and analyzed (negative control). To validate the system, $2 \mu \mathrm{l}$ tetracycline was inserted into the femoral canal before implantation (NT + tetra). Dashed line represents the bacterial inoculum. $n=3,{ }^{\star \star *} p<0.001$.

to titanium surfaces stimulates the ALP activity, the expression of the osteogenic and angiogenic markers, such as osteopontin, osteoprotegerin, hypoxia-inducible factor- $1 \alpha$, and vascular endothelial growth factor, and the matrix mineralization of mesenchymal stromal cells. ${ }^{32,58}$ In this study, we did not observe any effect on osteogenic differentiation nor antibacterial activity by PT $-\mathrm{Cu}$ implants, probably because the $\mathrm{Cu}^{2+}$ ion release from our biofunctionalized implants is substantially lower as compared to other studies that applied PEO. ${ }^{59,60}$ The results presented in the current study suggest that the synergistic effects of $\mathrm{Ag}$ and $\mathrm{Cu}$ make it possible to reduce the amount of the $\mathrm{Ag}$ released from the antibacterial surfaces while maintaining similar levels of antibacterial properties, thereby minimizing the potential adverse effects of $\mathrm{Ag}$ on the host cells. Moreover, given the fact that the $\mathrm{Ag}$ and $\mathrm{Cu}$ NPs are tightly embedded inside the oxide layer during the PEO process, the 
A

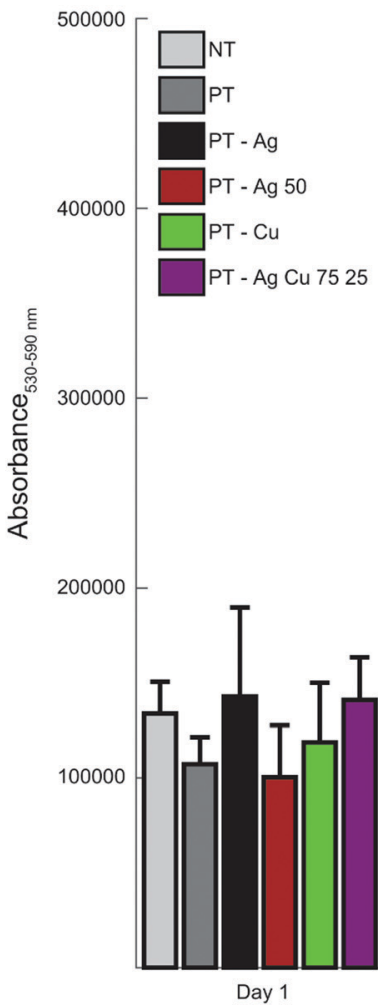

B

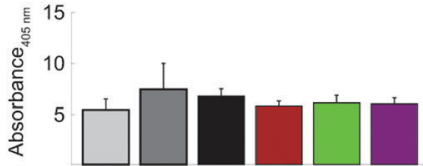

C

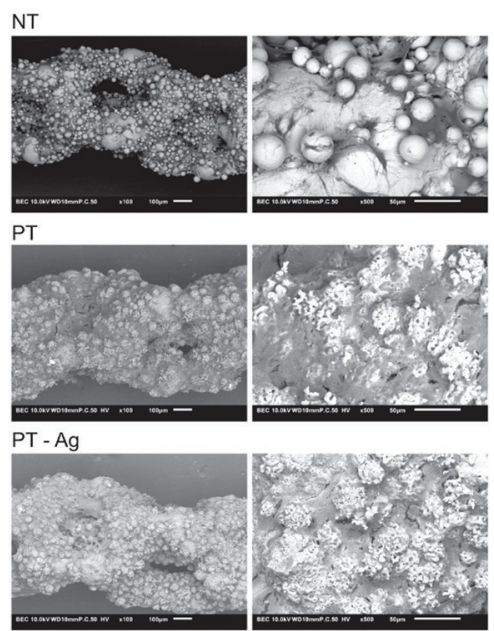

Day 3

Day 7

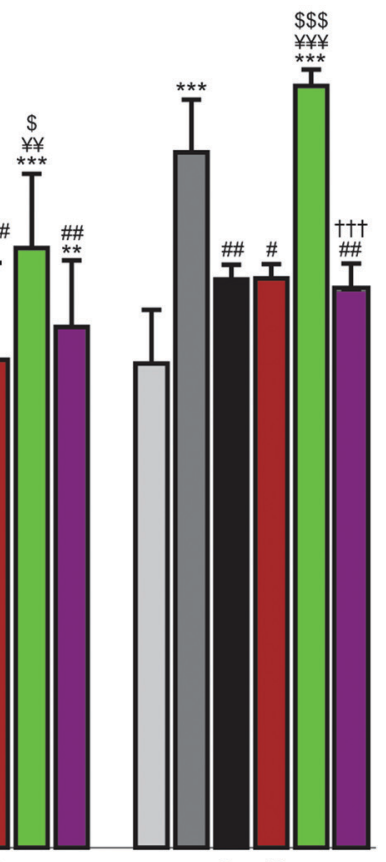

Day 11
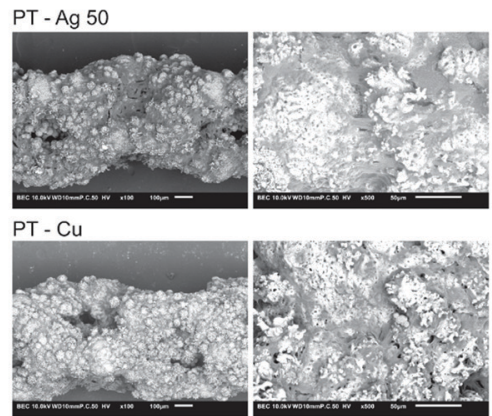

PT - Ag Cu 7525
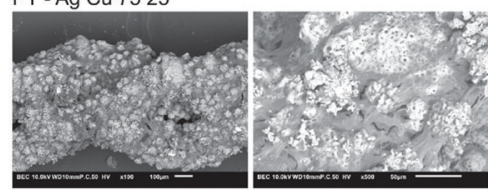

Fig. 7 The cytotoxicity assessment of the implants $(n=4)$ was performed using the MC3T3-E1 pre-osteoblasts. The osteogenic capacity of MC3T3-E1 cells cultured on the NT and biofunctionalized implants were determined as well ( $n=4$ per group). (A) The metabolic activity of MC3T3-E1 cells indicated in terms of the optical density $\left(\mathrm{OD}_{530-590 \mathrm{~nm}}\right)$ determined by Presto blue assay after 1, 3, 7, and 11 days of culture. (B) The ALP activity and (C) SEM images demonstrating the cell morphology and the spread of the MC3T3-E1 cells on the implants after 11 days of culture. Cell covered areas appear dark gray, while the implant substrate has a bright appearance. ${ }^{*} p<0.05,{ }^{*} p<0.01 * \star * p<0.001 .{ }^{*} v s$. NT, \# vs. PT, ¥vs. PT - Ag, \$vs. PT - Ag 50, †vs. PT - Cu.

circulation of the NPs and, thus, any adverse effects associated with that can be prevented.

In addition to the above-mentioned advantage, combining $\mathrm{Ag}$ and $\mathrm{Cu}$ on titanium surfaces reduces the likelihood of bacteria developing resistance against such antibacterial agents. ${ }^{61}$ Even though bacterial resistance to either $\mathrm{Ag}$ or $\mathrm{Cu}$ is not regarded currently as a threat for their clinical application, Ag-resistant MRSA strains have been isolated from nasal and wound sources in patients ${ }^{62}$ and mobile elements carrying $\mathrm{Ag}$ resistance are widely spread among pathogenic bacteria. ${ }^{63}$
Moreover, Staphylococcus aureus has demonstrated increased levels of resistance against $\mathrm{Ag}$ in a polymicrobial environment due to the presence of Ag-reducing factors secreted by other bacterial species. ${ }^{64}$ In addition, Cu-resistance inducing genes have been reported in Staphylococci, including MRSA, resulting in hyper-resistant strains. ${ }^{65,66}$ Therefore, preventing further development of resistance against $\mathrm{Ag}$ or $\mathrm{Cu}$ is essential for the extensive usability of these antibacterial agents. This further underlines the importance of exploiting the synergistic effects between multiple inorganic NPs. 
Apart from immediate bactericidal activity, long-term antibacterial leaching activity is desired, as IAI may arise even years after surgery stemming from a haematogenous origin. ${ }^{67}$ It is, therefore, of interest to create a reservoir of antibacterial agents on the surface of orthopedic biomaterials. In this study, the Ag and $\mathrm{Cu}$ NPs were firmly embedded and immobilized in the biofunctionalized $\mathrm{TiO}_{2}$ layer during the PEO process, thereby forming a reservoir that released significant levels of $\mathrm{Ag}$ and $\mathrm{Cu}$ ions for at least one month. We confirmed the purity of the NPs as well as preservation of shape and composition of the NPs after PEO biofunctionalization by transmission electron microscopy ${ }^{18}$ and EDS analysis. The $\mathrm{Ag}^{+}$and $\mathrm{Cu}^{2+}$ ion release was responsible for the clearance of planktonic bacteria in vitro and is important as the surrounding peri-implant tissue may form a niche for bacteria to infect the implant surface at later time points and generate systemic infections. ${ }^{12}$ The combination of $\mathrm{Ag}$ and $\mathrm{Cu}$ NPs affected the ion release profile of both $\mathrm{Ag}$ and $\mathrm{Cu}$ ions compared to implants that possessed either Ag or Cu NPs. The underlying mechanism for the altered $\mathrm{Ag}$ and $\mathrm{Cu}$ ion release was not studied, but may stem from the micro-galvanic coupling processes at the implant surface. ${ }^{68}$

Next to antibacterial leaching activity, antibacterial surfaces require contact-killing properties to extinguish adherent bacteria. ROS are known to play an important role in this process due to their extremely reactive nature, which also results in a short life-span. Previous studies have indicated the importance of ROS in bacterial killing by antibacterial surfaces containing either $\mathrm{Ag}$ or $\mathrm{Cu} .{ }^{68-71} \mathrm{We}$, therefore, investigated the generation of ROS from the implants with EPR and observed that PEO biofunctionalization resulted in the formation of both hydroxyl and methyl radicals. Furthermore, $\mathrm{Ag}$ incorporated into the implant surface enhanced the generation of hydroxyl radicals even further, whereas $\mathrm{Cu}$ NPs did not. Previously, we observed rutile and anatase $\mathrm{TiO}_{2}$ phases in the surface layer of the implants by X-ray diffraction. ${ }^{8}$ Anatase and rutile have shown to generate ROS and subsequent antibacterial activity. ${ }^{72,73}$ Therefore, ROS formed on the implant surfaces are likely to contribute to the observed antibacterial behavior in this study.

Given the fact that bacteria may infect both the implant surface and surrounding tissue, it is important to test multiple antibacterial properties in vitro such as the antibacterial leaching activity and contact killing. However, such studies lack the presence of the surrounding tissue. Therefore, we tested the implants in an ex vivo infection model consisting of murine femurs. ${ }^{8}$ In this model, specimens from both PT - Ag and PT $-\mathrm{Ag} \mathrm{Cu}$ groups with ratios of up to $75 \% \mathrm{Ag}$ and $25 \% \mathrm{Cu}$ demonstrated complete eradication of a bacterial inoculum, while those from the PT - Ag 50 group reduced the bacterial growth by two orders of magnitude. In the applied ex vivo setup, no distinction was made between the bacteria adhering to the implant or those that evaded into the adjacent bone tissue. In addition, in this model, no immune system is active that may aid in the eradication of the bacteria. Nonetheless, the results demonstrate a strong antibacterial behavior of all Ag NP-bearing implants.
The aforementioned antibacterial functionalities in vitro and ex vivo are generated through a single-step incorporation of both $\mathrm{Ag}$ and $\mathrm{Cu}$ NPs, and $\mathrm{Ca}$ and P elements in the electrolyte during the PEO process. PEO is highly suitable for the biofunctionalization of the surface of AM porous biomaterials, as it ensures a homogenous modification of the surface all over the implant surface, while not altering their mechanical properties. ${ }^{74}$ These properties make PEO highly suitable for the modification of AM meta-biomaterials, that are currently under development and may in the future significantly improve the fixation of bone scaffolds and orthopedic implants. ${ }^{75}$ Assigning antibacterial properties to these highly porous structures will be crucial to fight off IAI. Thus far, some studies have indicated that the enormous surface area of AM porous biomaterials allows for enhanced antibacterial performance of biofunctionalized implants bearing Ag NPs alone ${ }^{8}$ or in combination with antibiotics. $^{14,31}$

\section{Conclusions}

To develop novel antibacterial biomaterials that prevent IAI, Ti-6Al-4V implants were rationally designed, fabricated by SLM, and subsequently biofunctionalized by PEO with varying ratios of $\mathrm{Ag}$ and $\mathrm{Cu}$ NPs from 0 to $100 \%$. The material and morphological properties, release profiles, generation of reactive oxygen species, antibacterial behavior, and biocompatibility of the developed biomaterials were assessed using various material characterization techniques, antibacterial assays, and cytotoxicity tests. ICP-OES and EPR analysis revealed a sustained release of Ag and $\mathrm{Cu}$ ions up to 28 days and the generation of hydroxyl radicals in the first $2.5 \mathrm{~h}$, respectively resulting in strong antibacterial leaching and direct-contact activity against MRSA as well as a synergistic behavior between $\mathrm{Ag}^{+}$and $\mathrm{Cu}^{2+}$. Very strong antibacterial behaviors against both planktonic and adherent bacteria were also observed in vitro. Furthermore, the biofunctionalized implants containing both $\mathrm{Ag}$ and $\mathrm{Cu}$ NPs with ratios of up to $75 \% \mathrm{Ag}$ and $25 \% \mathrm{Cu}$ fully eradicated a bacterial inoculum in a murine ex vivo infection model. The synthesized implants did not induce cytotoxicity in preosteoblastic cells. Therefore, PEO biofunctionalization with Ag and $\mathrm{Cu}$ NPs is a promising strategy for preventing the infections associated with AM porous implants.

\section{Conflicts of interest}

There are no conflicts to declare.

\section{Acknowledgements}

The research for this paper was financially supported by the Prosperos project, funded by the Interreg VA Flanders - The Netherlands program, CCI grant no. 2014TC16RFCB046. 


\section{References}

1 C. L. Romano, S. Scarponi, E. Gallazzi, D. Romano and L. Drago, Antibacterial coating of implants in orthopaedics and trauma: a classification proposal in an evolving panorama, J. Orthop. Surg. Res., 2015, 10, 157.

2 D. Culliford, J. Maskell, A. Judge, C. Cooper, D. PrietoAlhambra, N. K. Arden and C.O.S. Group, Future projections of total hip and knee arthroplasty in the UK: results from the UK clinical practice research datalink, Osteoarthritis Cartilage, 2015, 23, 594-600.

3 S. M. Kurtz, E. Lau, H. Watson, J. K. Schmier and J. Parvizi, Economic burden of periprosthetic joint infection in the United States, J. Arthroplasty, 2012, 27, 61-67.

4 D. Campoccia, L. Montanaro and C. R. Arciola, A review of the biomaterials technologies for infection-resistant surfaces, Biomaterials, 2013, 34, 8533-8554.

5 T. F. Moriarty, R. Kuehl, T. Coenye, W. J. Metsemakers, M. Morgenstern, E. M. Schwarz, M. Riool, S. A. J. Zaat, N. Khana, S. L. Kates and R. G. Richards, Orthopaedic device-related infection: current and future interventions for improved prevention and treatment, EFORT Open Rev., 2016, 1, 89-99.

6 N. Stobie, B. Duffy, D. E. McCormack, J. Colreavy, M. Hidalgo, P. McHale and S. J. Hinder, Prevention of Staphylococcus epidermidis biofilm formation using a low-temperature processed silver-doped phenyltriethoxysilane sol-gel coating, Biomaterials, 2008, 29, 963-969.

7 K. Y. Yoon, J. Hoon Byeon, J. H. Park and J. Hwang, Susceptibility constants of Escherichia coli and Bacillus subtilis to silver and copper nanoparticles, Sci. Total Environ., 2007, 373, 572-575.

8 I. A. J. van Hengel, M. Riool, L. E. Fratila-Apachitei, J. WitteBouma, E. Farrell, A. A. Zadpoor, S. A. J. Zaat and I. Apachitei, Selective laser melting porous metallic implants with immobilized silver nanoparticles kill and prevent biofilm formation by methicillin-resistant Staphylococcus aureus, Biomaterials, 2017, 140, 1-15.

9 S. B. Goodman, Z. Yao, M. Keeney and F. Yang, The future of biologic coatings for orthopaedic implants, Biomaterials, 2013, 34, 3174-3183.

10 K. G. Neoh, X. Hu, D. Zheng and E. T. Kang, Balancing osteoblast functions and bacterial adhesion on functionalized titanium surfaces, Biomaterials, 2012, 33, 2813-2822.

11 J. P. Celis, D. Drees, M. Z. Huq, P. Q. Wu and M. De Bonte, Hybrid processes - a versatile technique to match process requirements and coating needs, Surf. Coat. Technol., 1999, 113, 165-181.

12 M. Riool, L. de Boer, V. Jaspers, C. M. van der Loos, W. J. B. van Wamel, G. Wu, P. H. S. Kwakman and S. A. J. Zaat, Staphylococcus epidermidis originating from titanium implants infects surrounding tissue and immune cells, Acta Biomater., 2014, 10, 5202-5212.

13 S. K. Nandi, A. Shivaram, S. Bose and A. Bandyopadhyay, Silver nanoparticle deposited implants to treat osteomyelitis, J. Biomed. Mater. Res., Part B, 2018, 106, 1073-1083.
14 S. Bakhshandeh, Z. Gorgin Karaji, K. Lietaert, A. C. Fluit, C. H. E. Boel, H. C. Vogely, T. Vermonden, W. E. Hennink, H. Weinans, A. A. Zadpoor and S. Amin Yavari, Simultaneous delivery of multiple antibacterial agents from additively manufactured porous biomaterials to fully eradicate planktonic and adherent staphylococcus aureus, ACS Appl. Mater. Interfaces, 2017, 9, 25691-25699.

15 N. Taniguchi, S. Fujibayashi, M. Takemoto, K. Sasaki, B. Otsuki, T. Nakamura, T. Matsushita, T. Kokubo and S. Matsuda, Effect of pore size on bone ingrowth into porous titanium implants fabricated by additive manufacturing: An in vivo experiment, Mater. Sci. Eng., C, 2016, 59, 690-701.

16 R. Hedayati, S. M. Ahmadi, K. Lietaert, B. Pouran, Y. Li, H. Weinans, C. D. Rans and A. A. Zadpoor, Isolated and modulated effects of topology and material type on the mechanical properties of additively manufactured porous biomaterials, J. Mech. Behav. Biomed. Mater., 2018, 79, 254-263.

17 S. M. Ahmadi, R. Hedayati, Y. Li, K. Lietaert, N. Tumer, A. Fatemi, C. D. Rans, B. Pouran, H. Weinans and A. A. Zadpoor, Fatigue performance of additively manufactured meta-biomaterials: The effects of topology and material type, Acta Biomater., 2018, 65, 292-304.

18 B. S. Necula, I. Apachitei, F. D. Tichelaar, L. E. Fratila-Apachitei and J. Duszczyk, An electron microscopical study on the growth of TiO2-Ag antibacterial coatings on Ti6Al7Nb biomedical alloy, Acta Biomater., 2011, 7, 2751-2757.

19 I. A. J. van Hengel, M. Riool, L. E. Fratila-Apachitei, J. WitteBouma, E. Farrell, A. A. Zadpoor, S. A. J. Zaat and I. Apachitei, Data on the surface morphology of additively manufactured Ti-6Al-4V implants during processing by plasma electrolytic oxidation, Data Brief, 2017, 13, 385-389.

20 A. Shivaram, S. Bose and A. Bandyopadhyay, Understanding long-term silver release from surface modified porous titanium implants, Acta Biomater., 2017, 58, 550-560.

21 S.-H. Uhm, J.-S. Kwon, D.-H. Song, E.-J. Lee, W.-S. Jeong, S. Oh, K.-N. Kim, E. H. Choi and K.-M. Kim, Long-Term antibacterial performance and bioactivity of plasmaengineered Ag-NPs/TiO2 nanotubes for bio-implants, J. Biomed. Nanotechnol., 2016, 12, 1890-1906.

22 B. S. Necula, L. E. Fratila-Apachitei, S. A. Zaat, I. Apachitei and J. Duszczyk, In vitro antibacterial activity of porous TiO2-Ag composite layers against methicillin-resistant Staphylococcus aureus, Acta Biomater., 2009, 5, 3573-3580.

23 Z. Gorgin Karaji, M. Speirs, S. Dadbakhsh, J.-P. Kruth, H. Weinans, A. Zadpoor and S. Amin Yavari, Additively manufactured and surface biofunctionalized porous nitinol, ACS Appl. Mater. Interfaces, 2017, 9, 1293-1304.

24 K. R. Shin, Y. S. Kim, G. W. Kim, H. W. Yang, Y. G. Ko and D. H. Shin, Effects of concentration of Ag nanoparticles on surface structure and in vitro biological responses of oxide layer on pure titanium via plasma electrolytic oxidation, Appl. Surf. Sci., 2015, 347, 574-582.

25 A. Nanda and M. Saravanan, Biosynthesis of silver nanoparticles from Staphylococcus aureus and its antimicrobial 
activity against MRSA and MRSE, Nanomedicine, 2009, 5, 452-456.

26 H. H. Lara, N. V. Ayala-Núñez, L. del Carmen Ixtepan Turrent and C. Rodríguez Padilla, Bactericidal effect of silver nanoparticles against multidrug-resistant bacteria, World J. Microbiol. Biotechnol., 2009, 26, 615-621.

27 S. L. Percival, P. G. Bowler and D. Russell, Bacterial resistance to silver in wound care, J. Hosp. Infect., 2005, 60, 1-7.

28 J. A. Lemire, J. J. Harrison and R. J. Turner, Antimicrobial activity of metals: mechanisms, molecular targets and applications, Nat. Rev. Microbiol., 2013, 11, 371-384.

29 D. Campoccia, L. Montanaro and C. R. Arciola, The significance of infection related to orthopedic devices and issues of antibiotic resistance, Biomaterials, 2006, 27, 2331-2339.

30 R. Y. Pelgrift and A. J. Friedman, Nanotechnology as a therapeutic tool to combat microbial resistance, Adv. Drug Delivery Rev., 2013, 65, 1803-1815.

31 M. Croes, S. Bakhshandeh, I. A. J. van Hengel, K. Lietaert, K. P. M. van Kessel, B. Pouran, B. C. H. van der Wal, H. C. Vogely, W. Van Hecke, A. C. Fluit, C. H. E. Boel, J. Alblas, A. A. Zadpoor, H. Weinans and S. Amin Yavari, Antibacterial and immunogenic behavior of silver coatings on additively manufactured porous titanium, Acta Biomater., 2018, 81, 315-327.

32 I. Burghardt, F. Luthen, C. Prinz, B. Kreikemeyer, C. Zietz, H. G. Neumann and J. Rychly, A dual function of copper in designing regenerative implants, Biomaterials, 2015, 44, 36-44.

33 L. Zou, J. Wang, Y. Gao, X. Ren, M. E. Rottenberg, J. Lu and A. Holmgren, Synergistic antibacterial activity of silver with antibiotics correlating with the upregulation of the ROS production, Sci. Rep., 2018, 8, 11131.

34 G. Jin, H. Qin, H. Cao, S. Qian, Y. Zhao, X. Peng, X. Zhang, X. Liu and P. K. Chu, Synergistic effects of dual $\mathrm{Zn} / \mathrm{Ag}$ ion implantation in osteogenic activity and antibacterial ability of titanium, Biomaterials, 2014, 35, 7699-7713.

35 J. A. Garza-Cervantes, A. Chavez-Reyes, E. C. Castillo, G. GarciaRivas, O. Antonio Ortega-Rivera, E. Salinas, M. Ortiz-Martinez, S. L. Gomez-Flores, J. A. Pena-Martinez, A. Pepi-Molina, M. T. Trevino-Gonzalez, X. Zarate, M. Elena Cantu-Cardenas, C. Enrique Escarcega-Gonzalez and J. R. Morones-Ramirez, Synergistic antimicrobial effects of silver/transition-metal combinatorial treatments, Sci. Rep., 2017, 7, 903.

36 F. C. Tenover and R. V. Goering, Methicillin-resistant Staphylococcus aureus strain USA300: origin and epidemiology, J. Antimicrob. Chemother., 2009, 64, 441-446.

37 K. L. Ong, S. M. Kurtz, E. Lau, K. J. Bozic, D. J. Berry and J. Parvizi, Prosthetic joint infection risk after total hip arthroplasty in the Medicare population, J. Arthroplasty, 2009, 24, 105-109.

38 H. Dale, A. M. Fenstad, G. Hallan, L. I. Havelin, O. Furnes, S. Overgaard, A. B. Pedersen, J. Karrholm, G. Garellick, P. Pulkkinen, A. Eskelinen, K. Makela and L. B. Engesaeter, Increasing risk of prosthetic joint infection after total hip arthroplasty, Acta Orthop., 2012, 83, 449-458.
39 A. W. Smith, Biofilms and antibiotic therapy: is there a role for combating bacterial resistance by the use of novel drug delivery systems?, Adv. Drug Delivery Rev., 2005, 57, 1539-1550.

40 D. Teterycz, T. Ferry, D. Lew, R. Stern, M. Assal, P. Hoffmeyer, L. Bernard and I. Uçkay, Outcome of orthopedic implant infections due to different staphylococci, Int. J. Infect. Dis., 2010, 14, 913-918.

41 S. Rtimi, D. D. Dionysiou, S. C. Pillai and J. Kiwi, Advances in catalytic/photocatalytic bacterial inactivation by nano $\mathrm{Ag}$ and $\mathrm{Cu}$ coated surfaces and medical devices, Appl. Catal., B, 2019, 240, 291-318.

42 M. K. Ballo, S. Rtimi, C. Pulgarin, N. Hopf, A. Berthet, J. Kiwi, P. Moreillon, J. M. Entenza and A. Bizzini, In vitro and in vivo effectiveness of an innovative silver-copper nanoparticle coating of catheters to prevent methicillinresistant staphylococcus aureus infection, Antimicrob. Agents Chemother., 2016, 60, 5349-5356.

43 B. Joshi, C. Regmi, D. Dhakal, G. Gyawali and S. W. Lee, Efficient inactivation of Staphylococcus aureus by silver and copper loaded photocatalytic titanate nanotubes, Prog. Nat. Sci.: Mater. Int., 2018, 28, 15-23.

44 S. Ferraris and S. Spriano, Antibacterial titanium surfaces for medical implants, Mater. Sci. Eng., C, 2016, 61, 965-978.

45 D. Karlin, Metalloenzymes, structural motifs, and inorganic models, Science, 1993, 261, 701-708.

46 J. T. Trevors and C. M. Cotter, Copper toxicity and uptake in microorganisms, J. Ind. Microbiol., 1990, 6, 77-84.

47 S. Chillappagari, A. Seubert, H. Trip, O. P. Kuipers, M. A. Marahiel and M. Miethke, Copper stress affects iron homeostasis by destabilizing iron-sulfur cluster formation in Bacillus subtilis, J. Bacteriol., 2010, 192, 2512-2524.

48 L. Macomber and J. A. Imlay, The iron-sulfur clusters of dehydratases are primary intracellular targets of copper toxicity, Proc. Natl. Acad. Sci. U. S. A., 2009, 106, 8344-8349.

49 A. Hiniker, J. F. Collet and J. C. Bardwell, Copper stress causes an in vivo requirement for the Escherichia coli disulfide isomerase DsbC, J. Biol. Chem., 2005, 280, 33785-33791.

50 C. Rademacher and B. Masepohl, Copper-responsive gene regulation in bacteria, Microbiology, 2012, 158, 2451-2464.

51 F. Altimira, C. Yanez, G. Bravo, M. Gonzalez, L. A. Rojas and M. Seeger, Characterization of copper-resistant bacteria and bacterial communities from copper-polluted agricultural soils of central Chile, BMC Microbiol., 2012, 12, 193.

52 J. R. Morones-Ramirez, J. A. Winkler, C. S. Spina and J. J. Collins, Silver enhances antibiotic activity against Gram-negative bacteria, Sci. Transl. Med., 2013, 5, $190 \mathrm{ra} 81$.

53 H. Wafa, R. J. Grimer, K. Reddy, L. Jeys, A. Abudu, S. R. Carter and R. M. Tillman, Retrospective evaluation of the incidence of early periprosthetic infection with silvertreated endoprostheses in high-risk patients, Bone Joint J, 2015, 97-B, 252-257.

54 J. Hardes, M. P. Henrichs, G. Hauschild, M. Nottrott, W. Guder and A. Streitbuerger, Silver-coated megaprosthesis of the proximal tibia in patients with sarcoma, J. Arthroplasty, 2017, 32, 2208-2213. 
55 F. Donati, G. Di Giacomo, S. D’Adamio, A. Ziranu, S. Careri, M. Rosa and G. Maccauro, Silver-coated hip megaprosthesis in oncological limb savage surgery, Biomed. Res. Int., 2016, 2016, 9079041.

56 C. J. Chung, R. T. Su, H. J. Chu, H. T. Chen, H. K. Tsou and J. L. He, Plasma electrolytic oxidation of titanium and improvement in osseointegration, J. Biomed. Mater. Res., Part B, 2013, 101, 1023-1030.

57 P. Whiteside, E. Matykina, J. E. Gough, P. Skeldon and G. E. Thompson, In vitro evaluation of cell proliferation and collagen synthesis on titanium following plasma electrolytic oxidation, J. Biomed. Mater. Res., Part A, 2010, 94, 38-46.

58 C. Wu, Y. Zhou, M. Xu, P. Han, L. Chen, J. Chang and Y. Xiao, Copper-containing mesoporous bioactive glass scaffolds with multifunctional properties of angiogenesis capacity, osteostimulation and antibacterial activity, Biomaterials, 2013, 34, 422-433.

59 W. Zhu, Z. Zhang, B. Gu, J. Sun and L. Zhu, Biological activity and antibacterial property of nano-structured $\mathrm{TiO} 2$ coating incorporated with $\mathrm{Cu}$ prepared by micro-arc oxidation, J. Mater. Sci. Technol., 2013, 29, 237-244.

60 D. Zhao, Y. Lu, X. Zeng, Z. Wang, S. Liu and T. Wang, Antifouling property of micro-arc oxidation coating incorporating Cu2O nanoparticles on Ti6Al4V, Surf. Eng., 2017, 33, 796-802.

61 B. Khameneh, R. Diab, K. Ghazvini and B. S. Fazly Bazzaz, Breakthroughs in bacterial resistance mechanisms and the potential ways to combat them, Microb. Pathog., 2016, 95, 32-42.

62 J. V. Loh, S. L. Percival, E. J. Woods, N. J. Williams and C. A. Cochrance, Silver resistance in MRSA isolated from wound and nasal sources in humans and animals, Int. Wound J., 2009, 6, 32-38.

63 K. Mijnendonckx, N. Leys, J. Mahillon, S. Silver and R. Van Houdt, Antimicrobial silver: uses, toxicity and potential for resistance, Biometals, 2013, 26, 609-621.

64 M. Muller, Bacterial silver resistance gained by cooperative interspecies redox behavior, Antimicrob. Agents Chemother., 2018, 62, DOI: 10.1128/AAC.00672-18.

65 A. T. Fessler, Q. Zhao, S. Schoenfelder, K. Kadlec, G. Brenner Michael, Y. Wang, W. Ziebuhr, J. Shen and S. Schwarz, Complete sequence of a plasmid from a bovine methicillinresistant Staphylococcus aureus harbouring a novel ica-like gene cluster in addition to antimicrobial and heavy metal resistance genes, Vet. Microbiol., 2017, 200, 95-100.
66 J. Purves, J. Thomas, G. P. Riboldi, M. Zapotoczna, E. Tarrant, P. W. Andrew, A. Londono, P. J. Planet, J. A. Geoghegan, K. J. Waldron and J. A. Morrissey, A horizontally gene transferred copper resistance locus confers hyperresistance to antibacterial copper toxicity and enables survival of community acquired methicillin resistant Staphylococcus aureus USA300 in macrophages, Environ. Microbiol., 2018, 20, 1576-1589.

67 K. Huotari, M. Peltola and E. Jamsen, The incidence of late prosthetic joint infections: a registry-based study of 112,708 primary hip and knee replacements, Acta Orthop., 2015, 86, 321-325.

68 G. Wang, W. Jin, A. M. Qasim, A. Gao, X. Peng, W. Li, H. Feng and P. K. Chu, Antibacterial effects of titanium embedded with silver nanoparticles based on electrontransfer-induced reactive oxygen species, Biomaterials, 2017, 124, 25-34.

69 H. J. Park, J. Y. Kim, J. Kim, J. H. Lee, J. S. Hahn, M. B. Gu and J. Yoon, Silver-ion-mediated reactive oxygen species generation affecting bactericidal activity, Water Res., 2009, 43, 1027-1032.

70 G. Applerot, J. Lellouche, A. Lipovsky, Y. Nitzan, R. Lubart, A. Gedanken and E. Banin, Understanding the antibacterial mechanism of $\mathrm{CuO}$ nanoparticles: revealing the route of induced oxidative stress, Small, 2012, 8, 3326-3337.

71 S. Meghana, P. Kabra, S. Chakraborty and N. Padmavathy, Understanding the pathway of antibacterial activity of copper oxide nanoparticles, RSC Adv., 2015, 5, 12293-12299.

72 X. Lin, J. Li, S. Ma, G. Liu, K. Yang, M. Tong and D. Lin, Toxicity of TiO2 nanoparticles to Escherichia coli: effects of particle size, crystal phase and water chemistry, PLoS One, 2014, 9, e110247.

73 H. N. Pantaroto, A. P. Ricomini-Filho, M. M. Bertolini, J. H. Dias da Silva, N. F. Azevedo Neto, C. Sukotjo, E. C. Rangel and V. A. R. Barao, Antibacterial photocatalytic activity of different crystalline $\mathrm{TiO} 2$ phases in oral multispecies biofilm, Dent. Mater., 2018, 34, e182-e195.

74 Z. Gorgin Karaji, R. Hedayati, B. Pouran, I. Apachitei and A. A. Zadpoor, Effects of plasma electrolytic oxidation process on the mechanical properties of additively manufactured porous biomaterials, Mater. Sci. Eng., C, 2017, 76, 406-416.

75 H. M. A. Kolken, S. Janbaz, S. M. A. Leeflang, K. Lietaert, H. H. Weinans and A. A. Zadpoor, Rationally designed metaimplants: a combination of auxetic and conventional metabiomaterials, Mater. Horiz., 2018, 5, 28-35. 